\title{
Cholesterol Depletion Blocks Redistribution of Lipid Raft Components and Insulin-Mimetic Signaling by Glimepiride and Phosphoinositolglycans in Rat Adipocytes
}

\author{
Günter Müller, Nils Hanekop, Susanne Wied, and Wendelin Frick \\ Aventis Pharma Germany, Frankfurt am Main, Germany \\ Accepted March 14, 2002
}

\begin{abstract}
Glycosylphosphatidylinositol-anchored plasma membrane (GPI) proteins, such as Gcel, the dually acylated nonreceptor tyrosine kinases (NRTKs), such as pp59 ${ }^{\mathrm{Lyn}}$, and the membrane protein, caveolin, together with cholesterol are typical components of detergent/carbonate-insoluble glycolipidenriched raft domains (DIGs) in the plasma membrane of most eucaryotes. Previous studies demonstrated the dissociation from caveolin and concomitant redistribution from DIGs of Gcel and pp59 $9^{\mathrm{Lyn}}$ in rat adipocytes in response to four different insulin-mimetic stimuli, glimepiride, phosphoinositolglycans, caveolin-binding domain peptide, and trypsin/NaCl-treatment. We now characterized the structural basis for this dynamic of DIG components.

Materials and Methods: Carbonate extracts from purified plasma membranes of basal and stimulated adipocytes were analyzed by high-resolution sucrose gradient centrifugation. Results: This process revealed the existence of two distinct species of detergent/carbonate-insoluble complexes floating at higher buoyant density and harboring lower amounts of cholesterol, caveolin, GPI proteins, and NRTKs (lcDIGs) compared to typical DIGs of high cholesterol content (hcDIGs). The four insulin-mimetic stimuli decreased by $40-70 \%$ and increased by 2.5 - to 5 -fold the amounts of GPI proteins and NRTKs at hcDIGs and lcDIGs, respectively.
\end{abstract}

Cholesterol depletion of adipocytes per se by incubation with methyl- $\beta$-cyclodextrin or cholesterol oxidase also caused translocation of GPI proteins and NRTKs from hcDIGs to lcDIGs and their release from caveolin in reversible fashion without concomitant induction of insulinmimetic signaling. Cholesterol depletion, however, reduced by $50-60 \%$ the stimulus-induced translocation as well as dissociation from hcDIGs-associated caveolin of GPI proteins and NRTKs, activation of NRTKs as well as insulinmimetic signaling and metabolic action. In contrast, insulinmimetic signaling induced by vanadium compounds was not significantly diminished by cholesterol depletion.

Conclusions: The data provide evidence that insulinmimetic signaling in rat adipocytes provoked by glimepiride, phosphoinositolglycans, caveolin-binding domain peptide, and trypsin/NaCl-treatment, but not vanadium compounds, relies on the dynamics of DIGs-the translocation of certain GPI proteins and NRTKs from hcDIGs to lcDIGs mediated by a trypsin/ $\mathrm{NaCl}$-sensitive cell surface component. The resultant stimulation of pp5 $59^{\mathrm{Lyn}}$ in course of its dissociation from caveolin and incorporation into lcDIGs in combination with an lcDIGsindependent signal seems to substitute for activation of the insulin receptor tyrosine kinase.

\section{Introduction}

Compartmentalization by distinct subcellular organelles playing a fundamental role in cellular function has been recognized for a long time. More recently, it has been hypothesized that some cell functions may be accomplished within compartments present in membranes as domains (1). Membrane domains are regions where the concentration of membrane components, lipids, and/or proteins, as well as

Correspondence and reprint requests should be addressed to: Dr. Günter Müller, Aventis Pharma Germany GmbH, Disease Group Metabolic Diseases, Industrial Park Höchst, Bldg. H825, 65926 Frankfurt am Main, Germany. Phone +4969-305-4271; fax +4969-305-81901; e-mail: Guenter.Mueller@aventis.com the physicochemical properties, are different from the surrounding environment. Currently, it is generally accepted that macro- and microdomains exist within the plane and across the two layers of the membrane, and that their presence may be associated with specific cell functions (2-4). Unlike the bulk of membranes, which are enriched in glycerophospholipids and packed in a disordered state, domains have a high (glyco)sphingolipid ([G]SL), glycosylphosphatidylinositol (GPI) lipid, and cholesterol content and appear to be packed in a liquid-ordered structure $(5,6)$. These differences make domains resistant to solubilization by cold non-ionic weak detergents or sodium carbonate resulting in low buoyant density membrane subfractions, which are now often being 
referred to as detergent/carbonate-insoluble glycolipidenriched raft domains (DIGs) $(1,7)$. These findings have been confirmed by alternative detergent-free techniques (8-10), arguing that domains are present in the membrane before detergent/carbonate treatment generated as self-organizing structures in a selfassembly process. The residence of lipid-modified signaling proteins, among them small and heterotrimeric $G$ proteins, nonreceptor tyrosine kinases (NRTKs) of the Src class and GPI-anchored cellsurface proteins (GPI proteins) in DIGs (11-13) suggests a role of DIGs in transmembrane signal transduction (14-16).

Similar to DIGs, caveolae (small flask-shaped invaginations of the plasma membrane present in most differentiated mammalian cell types and lacking the clathrin coating) are rich in cholesterol and (G)SL $(7,17,18)$. They are particularly abundant in adipocytes, where they increase in number in parallel to differentiation from fibroblasts (19). Caveolae may indeed form from DIGs in a process requiring the caveolae-specific structural membrane protein caveolin. Caveolin is found in the plasma membrane and intracellularly, but in the plasma membrane is confined to caveolae $(13,17)$. It is therefore used as a marker for these microdomains, which are involved in cellular transport processes (endocytosis, transcytosis, potocytosis, protein/lipid sorting) as well as transmembrane signaling $(11,16)$. For instance, Stralfors et al. demonstrated a critical dependence of the insulin receptor signal transduction on functional caveolae $(20,21)$. Evidence is thus growing that recruitment of specific proteins into DIGs operates as a general mechanism for the assembly of both protein and lipid components involved in membrane trafficking and signaling.

During the past two decades, a number of exogenous structurally completely different stimuli have been described that activate the insulin signaling cascade by triggering insulin receptor-independent tyrosine phosphorylation of the insulin receptor substrate proteins (IRS) and elicit a series of metabolic insulinmimetic actions, such as stimulation of glucose transport and nonoxidative glucose metabolism as well as inhibition of lipolysis, in insulin-responsive target cells, such as isolated or cultures adipocytes, among them: (i) isolated or synthetic phosphoinositolglycan (PIG) compounds (22-27), which resemble the polar core glycan head group of GPI lipids and GPI protein membrane anchors (28); (ii) the sulfonylurea drug, glimepiride, which lowers blood glucose by stimulation of insulin release and possibly by augmenting peripheral glucose disposal in insulin-independent fashion (29); (iii) the synthetic caveolin-binding domain peptide (CBDP) derived from the caveolin-interacting sequence of the dually acylated NRTK pp59 $9^{\mathrm{Lyn}}$ (30-32); and (iv) limited concentrations of trypsin and $\mathrm{NaCl}$, which led to inactivation of the trypsin/ $/ \mathrm{NaCl} /$ $\mathrm{N}$-ethylmaleimide (NEM)-sensitive adipocyte cellsurface component (CIR) required for insulin-mimetic PIG action (33). A common prerequisite for insulin- mimetic signaling in adipocytes by these stimuli has been found to rely on activation of $\mathrm{pp} 59^{\mathrm{Lyn}}$, which interacts with DIGs-associated caveolin in the basal state but dissociates upon stimulation $(31,32)$. The relationship between association of signaling proteins (via their caveolin-binding domain) with (the caveolin-scaffolding domain of) caveolin, which according to the caveolae signaling hypothesis is responsible for keeping them in the basal low-activity but signalingcompetent state $(12,16,30,34)$, and their localization at DIGs remained unclear so far. We recently observed movement of the GPI protein, Gcel, and the NRTKs, pp5 $59^{\mathrm{Lyn}}$ and ppl25 ${ }^{\mathrm{Fak}}$, from DIGs to so-called nonDIG areas of the adipocyte plasma membrane in response to synthetic PIG and glimepiride $(32,35)$. This was accompanied by tyrosine phosphorylation and activation of the NRTKs. However, the nature of these non-DIG areas remained ill-defined, leaving open the possibility of their non-identity with bulk plasma membranes but identify with membrane (micro) domains distinct from typical DIGs.

Here we found that insulin-mimetic signaling by PIG41, glimepiride, CBDP and trypsin/ $\mathrm{NaCl}$ critically depends on the translocation of GPI proteins and pp5 $9^{\mathrm{Lyn}}$ from typical DIGs to DIGs of higher buoyant density and lower cholesterol content but not to bulk plasma membranes. These data provide evidence for heterogeneity and dynamics within DIGs and their functional relevance for signal transduction processes, such as cross-talk to the insulin signaling cascade.

\section{Materials and Methods}

Anti-caveolin- 1 antibody (1:500 dilution; monoclonal, clone C060, raised against a peptide corresponding to aa 1-97 of human caveolin-1), anticaveolin-2 antibody (monoclonal, clone 65), and anti-phosphotyrosine antibody (monoclonal, clones PY20 and 4G10) were purchased from Transduction Laboratories (Lexington, KY, USA). Anti-IRS-1 antibody (total human recombinant IRS-1, rabbit) was obtained from Biotrend (Cologne, Germany). Anti-insulin receptor $\beta$-subunit (IR $\beta$ ) antibody (total human recombinant IR $\beta$, monoclonal) was provided by Upstate Biotechnology (Lake Placid, NY, USA). Methyl- $\beta$-cyclodextrin (m $\beta C D$ ) and $N$-ethylmaleimide (NEM) were purchased from Sigma (Deisenhofen, Germany). Proteinase inhibitors, cholesterol oxidase (CO), and adenosine deaminase were from Roche Molecular Biochemicals (Mannheim, Germany). POV (bpV[phen] = potassium bisperoxo[1,10-phenanthroline]oxovanadate[V]) was obtained from Calbiochem (Bad Soden, Germany). Precast gels were purchased from Novex (San Diego, CA, USA). Polyvinylidene difluoride membranes (Immobilon-P) were obtained from Millipore (Eschborn, Germany). The synthesis of human recombinant insulin, PIG41, glimepiride, and CBDP (Department of Medicinal Chemistry/Biotechnology of Aventis Pharma, Frankfurt am Main, Germany) 
and the sources for the other materials used have been described previously (22-24,31-35).

\section{Preparation and Incubation of Rat Diaphragms}

Intact diaphragms (with rib cage attached) from male Wistar rats (60-80 g, fed ad libitum) killed by cervical dislocation as described previously (22) were washed once with saline and once with KRO-buffer (140 mM NaCl, $6 \mathrm{mM} \mathrm{KCl,} 2 \mathrm{mM}$ $\mathrm{CaCl}_{2}, 1 \mathrm{mM} \mathrm{MgSO}{ }_{4}, 1.2 \mathrm{mM} \mathrm{KH} \mathrm{PO}_{4}, 0.1 \% \mathrm{BSA}$, $25 \mathrm{mM}$ Hepes/KOH, pH 7.5, equilibrated with $\mathrm{O}_{2}$ ) containing $5 \mathrm{mM}$ glucose and then dissected into halves (hemidiaphragms). After incubation (30 min, $30^{\circ} \mathrm{C}$ ) in $20 \mathrm{ml}$ of $\mathrm{KRO}$ buffer containing $5 \mathrm{mM}$ glucose under continuous bubbling with $95 \% \mathrm{O}_{2} / 5 \%$ $\mathrm{CO}_{2}$, followed by two 15-min periods of incubation in the presence of insulin/PIG41/glimepiride with fresh buffer under the same conditions, the hemidiaphragms were washed with KRO buffer containing $2 \mathrm{mM}$ pyruvate and $5 \mathrm{mM}$ sucrose. Total cell lysates were prepared by homogenization in $10 \mathrm{mM}$ Tris/ $\mathrm{HCl}, \mathrm{pH} 7.4$, I mM EDTA, 0.5 mM EGTA, $0.25 \mathrm{M}$ sucrose, $50 \mathrm{mM} \mathrm{NaF}, 5 \mathrm{mM}$ sodium pyrophosphate, $10 \mathrm{mM}$ glycerol-3-phosphate, $5 \mu \mathrm{M}$ microcystin, $10 \mu \mathrm{M}$ leupeptin, $1 \mu \mathrm{M}$ pepstatin, $1 \mu \mathrm{M}$ aprotinin, $4 \mathrm{mM}$ iodoacetate, $100 \mu \mathrm{M}$ PMSF using a motordriven Teflon-in-glass homogenizer at $4^{\circ} \mathrm{C}$.

\section{Preparation and Incubation of Rat Adipocytes}

Adipocytes were isolated by collagenase digestion from epididymal fat pads of male Sprague Dawley rats $(140-160 \mathrm{~g}$, fed ad libitum) $(22,23)$ and incubated in KRH (140 mM NaCl, $4.7 \mathrm{mM} \mathrm{KCl}, 2.5 \mathrm{mM}$ $\mathrm{CaCl}_{2}, 1.2 \mathrm{mM} \mathrm{MgSO}{ }_{4}, 1.2 \mathrm{mM} \mathrm{KH} \mathrm{PO}_{4}, 20 \mathrm{mM}$ Hepes/KOH, pH 7.4, containing 2\% (w/v) BSA, $100 \mu \mathrm{g} / \mathrm{ml}$ gentamycin, $100 \mathrm{nM}$ 1-methyl-2phenylethyladenosine, $0.5 \mathrm{U} / \mathrm{ml}$ adenosine deaminase, $1 \mathrm{mM}$ sodium pyruvate, and $5.5 \mathrm{mM}$ D-glucose) in the presence of PIG4l or glimepiride or were electroporated with CBDP $(31)$ at $37^{\circ} \mathrm{C}$ in a shaking water bath under constant bubbling with $5 \%$ $\mathrm{CO}_{2} / 95 \% \mathrm{O}_{2}$ for the periods indicated.

\section{Inactivation of CIR by Trypsin/NaCl- or NEM-Treatment of Rat Adipocytes}

For trypsin/ $\mathrm{NaCl}$ treatment, $2.5 \mathrm{ml}$ of adipocyte suspension $\left(3.5 \times 10^{6}\right.$ cells $\left./ \mathrm{ml}\right)$ in $\mathrm{KRH}$ containing $5 \mathrm{mM}$ glucose was incubated $\left(20 \mathrm{~min}, 30^{\circ} \mathrm{C}\right)$ in the presence of $100 \mu \mathrm{g} / \mathrm{ml}$ trypsin (33). Soy bean trypsin inhibitor (final concentration $100 \mu \mathrm{g} / \mathrm{ml}$ ) and $2.5 \mathrm{ml}$ of $\mathrm{KRH}$ containing $1 \mathrm{M} \mathrm{NaCl}, 0.5 \% \mathrm{BSA}$ were added. For NEM treatment, $1 \mathrm{ml}$ of adipocyte suspension $\left(3.5 \times 10^{6}\right.$ cells $\left./ \mathrm{ml}\right)$ in $\mathrm{KRH}$ containing $5 \mathrm{mM}$ glucose was incubated $\left(30 \mathrm{~min}, 22^{\circ} \mathrm{C}\right)$ with NEM (1.5 $\mathrm{mM}$ final concentration) and then with DTT (15 mM final concentration). After further incubation $\left(10 \mathrm{~min}, 22^{\circ} \mathrm{C}\right)$, the trypsin/ $\mathrm{NaCl}-$ or NEMtreated cells were centrifuged $(1500 \times g, 5 \mathrm{~min}$, swing-out rotor). Following removal of the infranatant, the cell suspension (about $0.5 \mathrm{ml}$ ) was supplemented with $10 \mathrm{ml}$ of KRH containing $0.5 \%$ BSA and then centrifuged again $(500 \times g, 1 \mathrm{~min}$, swing-out rotor). After two additional washing steps, the final cell suspension was adjusted to $25 \mathrm{ml}$ of $\mathrm{KRH}$ containing $0.5 \% \mathrm{BSA}, 50 \mu \mathrm{M}$ glucose, and $1 \mathrm{mM}$ sodium pyruvate. For lipogenesis, 0.2 -ml portions were assayed to monitor the loss of responsiveness toward PIG41 (see ref. 33). Control cells received water instead of trypsin and were subjected to the same centrifugation, termination (presence of $\mathrm{NaCl}$ ), and washing procedures as the trypsintreated cells.

\section{Preparation of Total Plasma Membranes}

Rat adipocytes $\left(5 \times 10^{7}\right.$ cells) were washed and immediately homogenized in $10 \mathrm{ml}$ of lysis buffer (25 mM Tris/HCl, pH 7.4, 0.5 mM EDTA, $0.25 \mathrm{mM}$ EGTA, $0.25 \mathrm{M}$ sucrose, $50 \mathrm{mM} \mathrm{NaF}, 5 \mathrm{mM}$ sodium pyrophosphate, $25 \mathrm{mM}$ glycerol-3-phosphate, and $1 \mathrm{mM}$ sodium orthovanadate, supplemented with protease inhibitors [10 $\mu \mathrm{g} / \mathrm{ml}$ leupeptin, $2 \mu \mathrm{M}$ pepstatin, $10 \mu \mathrm{g} / \mathrm{ml}$ aprotinin, $5 \mu \mathrm{M}$ antipain, $5 \mathrm{mM}$ iodoacetate, $200 \mu \mathrm{M}$ PMSF, $4 \mathrm{mM}$ benzamidine]) using a motor-driven Teflon-in-glass homogenizer (10 strokes with a loosely fitting pestle) at $22^{\circ} \mathrm{C}$ (36). The defatted postnuclear infranatant $(1500 \times g$, $5 \mathrm{~min})$ was centrifuged $(12,000 \times g, 15 \mathrm{~min})$. The pellet was suspended in $10 \mathrm{ml}$ of lysis buffer, layered on top of a $5-\mathrm{ml}$ cushion of $38 \%(\mathrm{w} / \mathrm{v})$ sucrose, $25 \mathrm{mM}$ Tris/HCl ( $\mathrm{pH} 7.4), 1 \mathrm{mM}$ EDTA, and centrifuged $(110,000 \times g, 1 \mathrm{hr})$. The membranes at the interface between the two layers $(0.5 \mathrm{ml})$ were removed and layered on top of an 8-ml cushion of $28 \%$ Percoll, $0.25 \mathrm{M}$ sucrose, $25 \mathrm{mM}$ Tris/HCl (pH 7.0), and $1 \mathrm{mM}$ EDTA. After centrifugation $(45,000 \times g$, $30 \mathrm{~min})$, the purified total plasma membranes were withdrawn from the lower third of the gradient $(0.5 \mathrm{ml})$ and pelleted $(200,000 \times g, 90 \mathrm{~min})$.

\section{Preparation of Detergent-Insoluble Glycolipid-Enriched} Raft Domains (hcDIGs and lcDIGs)

Purified pelleted plasma membranes $(0.5-1 \mathrm{mg})$ were suspended in $1.5 \mathrm{ml}$ of $0.5 \mathrm{M} \mathrm{Na}_{2} \mathrm{CO}_{3}$ (pH 11) containing phosphatase and protease inhibitors (50 mM NaF, $5 \mathrm{mM}$ sodium pyrophosphate, $10 \mu \mathrm{M}$ okadaic acid, $1 \mathrm{mM}$ sodium orthovanadate, $20 \mu \mathrm{M}$ leupeptin, $5 \mu \mathrm{M}$ pepstatin, $1 \mu \mathrm{M}$ aprotinin, $5 \mathrm{mM}$ iodoacetate, $200 \mu \mathrm{M}$ PMSF, $1 \mathrm{mM}$ EDTA) and sonicated (three 30 -sec bursts with 1-min intervals on ice, Branson B-12, power stage 4). The suspension was then mixed with an equal volume of $85 \%$ sucrose in $15 \mathrm{mM}$ Mes/KOH (pH 6.5), $75 \mathrm{mM} \mathrm{NaCl}$, $0.25 \mathrm{M} \mathrm{Na}_{2} \mathrm{CO}_{3}$, and overlayed with 1.5-ml cushions each of $42.5 \%, 35 \%, 28 \%, 22 \%, 15 \%$, and $5 \%$ sucrose in the same medium, and centrifuged to equilibrium $\left(230,000 \times g\right.$, Beckman SW4l rotor, $\left.18 \mathrm{hr}, 4^{\circ} \mathrm{C}\right)$. The light-scattering opalescent bands of flocculent material at the $15-22 \%$ (fractions 4 and 5 ) and $28-35 \%$ (fractions 8 and 9) sucrose interfaces as well as the material of the $42.5 \%$ cushion (fractions 12-15) 
were collected as hcDIGs, lcDIGs and detergent/ carbonate-soluble plasma membrane proteins, respectively, using a 19-gauge needle and a syringe $(0.75 \mathrm{ml}$ per fraction). Density of the fractions was determined by measuring the refractive index. For (co)immunoprecipitation, the hc/lcDIG-containing fractions were diluted 5-fold with $15 \mathrm{mM}$ Mes (pH 6.5), $75 \mathrm{mM} \mathrm{NaCl}, 1 \mathrm{mM}$ sodium orthovanadate, $50 \mathrm{mM} \mathrm{NaF}$, protease inhibitors, and $1 \%$ Nonidet-P40, incubated $\left(1 \mathrm{hr}, 4^{\circ} \mathrm{C}\right)$, collected by centrifugation $\left(48,000 \times \mathrm{g}, 30 \mathrm{~min}, 4^{\circ} \mathrm{C}\right)$, then resuspended in nondissociating buffer $(10 \mathrm{mM}$ Tris/ $\mathrm{HCl}, \mathrm{pH} 7.4,150 \mathrm{mM} \mathrm{NaCl}, 5 \mathrm{mM}$ EDTA, $0.5 \mathrm{mM}$ EGTA, $1 \mathrm{mM}$ sodium orthovanadate, $50 \mathrm{mM} \mathrm{NaF}$, and protease inhibitors) or, alternatively, in dissociating buffer (nondissociating buffer containing $60 \mathrm{mM} \quad \beta$-octylthioglucoside and $0.3 \%$ deoxycholate) as indicated, subsequently incubated ( $1 \mathrm{hr}$, on ice) and finally used for photoaffinity or NEM labeling. For direct analysis, hc/lcDIGs resuspended in dissociating buffer or carbonate-soluble proteins were precipitated with 5\% TCA and then subjected to SDS-PAGE and immunoblotting. hcDIGs, lcDIGs, and carbonate-soluble plasma membrane proteins are characterized by enrichment/deprivement, respectively, of caveolin-1 (8.5- to 11-fold, 3.7- to 7.5fold, and 0.3- to 0.6-fold, respectively), caveolin-2 (5- to 6.5-fold, 3.1-to 4-fold, and 0.1- to 0.2-fold, respectively) and cholesterol (3- to 3.5-fold corresponding to $0.81 \pm 0.12 \mathrm{nmol} / \mu \mathrm{g}$ protein, 2 - to 2.5 fold corresponding to $0.55 \pm 0.10 \mathrm{nmol} / \mu \mathrm{g}$ protein and 0.5 - to 0.8 -fold corresponding to $0.13 \pm 0.05$ $\mathrm{nmol} / \mu \mathrm{g}$ protein, respectively) compared with total purified plasma membranes (in dissociating buffer).

\section{Photoaffinity Labeling of Glycolipid-Anchored} cAMP-Binding Ectoprotein (Gcel)

Purified total plasma membranes and hc/lcDIGs (5-10 $\mu \mathrm{g}$ protein) in $25 \mu \mathrm{l}$ of dissociating buffer were incubated $\left(30 \mathrm{~min}, 4^{\circ} \mathrm{C}\right)$ with $50 \mu \mathrm{Ci} 8-\mathrm{N}_{3}-\left[{ }^{32} \mathrm{P}\right]$ cAMP $(0.5 \mathrm{nmol})$ in $25 \mu \mathrm{l}$ of $10 \mathrm{mM}$ Tris/ $\mathrm{HCl}(\mathrm{pH} 7.4)$, $1 \mathrm{mM}$ EDTA, $0.5 \mathrm{mM}$ EGTA, $140 \mathrm{mM} \mathrm{NaCl}, 10 \mathrm{mM}$ $\mathrm{MgCl}_{2}, 2 \mathrm{mM} \mathrm{MnCl}, 1 \mathrm{mM}$ isobutylmethylxanthine, $1 \mathrm{mM}$ DTT, $1 \mathrm{mM}$ AMP, and protease inhibitors in the wells of microtiter plates (96-formate) and then irradiated with UV light $\left(254 \mathrm{~nm}, 8000 \mu \mathrm{W} / \mathrm{cm}^{2}\right)$ at a distance of $0.5 \mathrm{~cm}$ for $1 \mathrm{~min}(36,37)$. Subsequently, the photoaffinity labeling reaction was quenched by addition of $100 \mu \mathrm{l}$ of the same buffer containing $10 \mathrm{mM}$ cAMP. Gcel was precipitated with 5\% TCA and then analyzed by SDS-PAGE and phosphorimaging.

\section{NEM Labeling of CIR}

hc/lcDIGs suspended in $200 \mu \mathrm{l}$ of dissociating buffer were incubated $\left(15 \mathrm{~min}, 25^{\circ} \mathrm{C}\right)$ with $25 \mu \mathrm{Ci}$ $N$-ethyl $\left[2,3-{ }^{14} \mathrm{C}\right]$ maleimide $(10 \mathrm{mCi} / \mathrm{mmol})$ (33). After addition of DTT ( $50 \mathrm{mM}$ final concentration), radiolabeled proteins were precipitated with $5 \%$ TCA and then analyzed by SDS-PAGE and phosphorimaging.

\section{Immunoprecipitation}

Total cell lysates (25-50 $\mu \mathrm{g}$ protein), filtered through a $0.22-\mu \mathrm{m}$ pore size filter for removal of fat, or hc/lcDIGs in nondissociating/dissociating buffer (10-15 $\mu \mathrm{g}$ protein) were precleared with protein G/A-Sepharose and then incubated with anti-caveolin-1 (2.5 $\mu \mathrm{g} / \mathrm{sample})$, anti-IRS I (10 $\mu \mathrm{g} / \mathrm{sample})$, anti-pp59 ${ }^{\text {Lyn }}$ ( $\left.5 \mu \mathrm{g} / \mathrm{sample}\right)$, or anti-IR $\beta$ (1:175 dilution) antibodies preadsorbed to $20 \mu \mathrm{l}$ of protein G/A-Sepharose $(50 \mathrm{mg} / \mathrm{ml})(23,31)$. After incubation $\left(4 \mathrm{hr}, 4^{\circ} \mathrm{C}\right.$, with rocking) and centrifugation $(5000 \times \mathrm{g}$, $2 \mathrm{~min})$, the collected immune complexes were washed four times $(10 \mathrm{mM}$ Tris/ $\mathrm{HCl}, \mathrm{pH} 8.0,150 \mathrm{mM} \mathrm{NaCl}$, $6 \mathrm{mM}$ EDTA, $1 \%$ Triton X-100, $1 \mathrm{mM} \mathrm{Na} \mathrm{VO}_{4}$, $10 \mu \mathrm{g} / \mathrm{ml}$ aprotinin, $1 \mathrm{mM}$ benzamidine, and $100 \mu \mathrm{M}$ PMSF), suspended in $50 \mu \mathrm{l}$ of sample buffer and then analyzed by SDS-PAGE (4-12\% Bis-Tris precast gel, $\mathrm{pH}$ 6.4, Mes/SDS running buffer) under reducing conditions. The recovery in the amount of immunoprecipitated protein was normalized by homologous immunoblotting. The centrifugation conditions for collection of the protein A/G Sepharose-bound immune complexes did not lead to sedimentation of nondissociated hcDIGs to any significant degree according to caveolin immunoblotting. The coimmunoprecipitation of proteins with caveolin from dissociated hcDIGs was specific for hcDIGsassociated components that directly interact with caveolin, such as pp59 $9^{\mathrm{Lyn}} \cdot \mathrm{pp} 59^{\mathrm{Lyn}}$ was not immunoprecipitated using nonimmune IgG instead of anticaveolin antibody. In contrast, Gcel did not coimmunoprecipitate with caveolin from dissociated hcDIGs, but was recovered with nondissociated hcDIGs directly or via coimmunoprecipitation with caveolin (35).

\section{Immunoblotting}

After SDS-PAGE and transfer of the proteins to polyvinylidene difluoride membranes $(2 \mathrm{hr}$ at $400 \mathrm{~mA}$ in $20 \%$ methanol, $192 \mathrm{mM}$ glycine, $25 \mathrm{mM}$ Tris/ $\mathrm{HCl}, 0.005 \%$ SDS), the blocked membrane ( $1 \mathrm{hr}$ in $20 \mathrm{mM}$ Tris/ $\mathrm{HCl}, \mathrm{pH} 7.6,150 \mathrm{mM} \mathrm{NaCl}, 0.05 \%$ Tween $20,0.1 \%$ Brij, $0.01 \%$ Nonidet-P40, $1 \%$ ovalbumin, $1 \%$ BSA, $0.1 \%$ milk powder) was incubated $\left(2 \mathrm{hr}, 25^{\circ} \mathrm{C}\right)$ with anti-phosphotyrosine antibodies $(0.5 \mu \mathrm{g}$ of each of the two antibodies per milliliter of blocking buffer) $(23,31,32)$. Thereafter, the washed membrane was incubated $\left(1 \mathrm{hr}, 25^{\circ} \mathrm{C}\right)$ with horseradish peroxidase-coupled goat anti-mouse IgG antibody (1:5000 in blocking buffer), again washed, and finally developed using the enhanced chemiluminescence method.

\section{Assays for Metabolic Insulin Action}

For determination of glucose transport, washed adipocytes were incubated with 2-deoxy-D-[2, $6-^{3} \mathrm{H}$ ]glucose $\left(50 \mu \mathrm{M}, 0.33 \mu \mathrm{Ci} / \mathrm{ml} ; 20 \mathrm{~min}, 37^{\circ} \mathrm{C}\right)$ in the absence or presence (for correction of nonspecific uptake) of $20 \mu \mathrm{M}$ cytochalasin B and then centrifuged through a oil layer prior to liquid scintillation 
counting $(22,23,37)$. Lipogenesis was measured as incorporation of glucose into toluene-extractable lipids after addition of $\left[3-{ }^{3} \mathrm{H}\right]$ glucose $(0.4 \mu \mathrm{Ci})$ to the adipocyte suspension adjusted to $2 \mathrm{mM}$ total final glucose concentration (to monitor predominantly stimulation of the esterification rather than the glucose transport step during overall lipid synthesis) and incubation $\left(90 \mathrm{~min}, 37^{\circ} \mathrm{C}\right)(22,23)$. Glycogenesis was determined by incubation $\left(20 \mathrm{~min}, 30^{\circ} \mathrm{C}\right)$ of the washed hemidiaphragms with $15 \mathrm{ml}$ of KRO-Hepes buffer containing $2 \mathrm{mM}\left[\mathrm{U}^{14}{ }^{14} \mathrm{C}\right]$ glucose $(5 \mu \mathrm{Ci})$ under continuous bubbling with $95 \% \quad \mathrm{O}_{2} / 5 \% \quad \mathrm{CO}_{2}$. Subsequent processing of the hemidiaphragms (removal of the rib cage, washing, homogenization, centrifugation) and determination of the amount of radiolabeled glycogen (ethanol precipitation, liquid scintillation counting) were performed as described previously $(22,23)$. Glycogen synthase (GS) activity was assayed as incorporation of $\left[{ }^{14} \mathrm{C}\right]$ glucose from UDP- $\left[{ }^{14} \mathrm{C}\right]$ glucose $(4 \mu \mathrm{Ci}, 130 \mu \mathrm{M}$ final concentration) into ethanol-precipitable glycogen by a postnuclear fraction from total defatted homogenate of diaphragms $\left(16,000 \times g, 20 \mathrm{~min}, 4^{\circ} \mathrm{C}\right)$ during incubation $\left(20 \mathrm{~min}, 30^{\circ} \mathrm{C}\right)$ in the presence of $0.066 / 6.6 \mathrm{mM}$ glucose-6-phosphate and calculated as fractional velocity as described previously $(22,23)$.

\section{Preparation of $m \beta C D$ Cholesterol Inclusion Complexes}

Thirty milligrams of cholesterol in methanol/chloroform $(2 / 1 \mathrm{v} / \mathrm{v})$ were added in small aliquots to $1 \mathrm{~g}$ $\mathrm{m} \beta \mathrm{CD}$ in solution $(5 \% \mathrm{w} / \mathrm{v})$ at $80^{\circ} \mathrm{C}(38)$. The mixtures were stirred at $80^{\circ} \mathrm{C}$ until complete dissolution of the initially precipitating steroid indicating its stable complexing by $\mathrm{m} \beta \mathrm{CD}$ and then stored at $22^{\circ} \mathrm{C}$ until use on the same day.

\section{Cholesterol Determination}

Purified total plasma membranes, and hc/lcDIGs resuspended in nondissociating buffer were collected by centrifugation $\left(48,000 \times g, 30 \mathrm{~min}, 4^{\circ} \mathrm{C}\right)$. Lipids were extracted with 2-propanol. Cholesterol was quantitatively evaluated with the CO method (39) and spectrofluorometric determination of the amount of $\mathrm{H}_{2} \mathrm{O}_{2}$ generated (assay kit from Roche Molecular Diagnostics).

\section{Miscellaneous}

Electroporation of adipocytes with CBDP was performed as described previously (31). Protein concentration was determined using the BCA protein determination kit from Pierce (Rockford, IL, USA) and BSA as calibration standard. Chemiluminescent detection using ECL reagents (Amersham, Freiburg, Germany) and quantitative evaluation by the LumiImager system (Roche Molecular Diagnostics, Penzberg, Germany) were performed according to the manufacturers' instructions. Phosphorimages were processed and quantified by computer-assisted video densitometry using the
Storm 860 Phosphorimager system (Molecular Dynamics, Gelsenkirchen, Germany).

\section{Results \\ Cholesterol Depletion of the Adipocyte Plasma Membrane Unmasks Two Distinct Types of DIGs}

Carbonate extracts from purified plasma membranes of isolated rat adipocytes were analyzed by centrifugation through discontinuous high-resolution sucrose density gradients consisting of six sucrose cushions between $5 \%$ and $42.5 \%$, which were used in the present study for the first time. Two distinct species of detergent/carbonate-insoluble high-buoyant-density complexes (as defined by resistance toward $0.5 \mathrm{M} \mathrm{Na}_{2} \mathrm{CO}_{3}[\mathrm{pH} 11]$ as well as $1 \% \mathrm{TX}-100$ [at $\left.4^{\circ} \mathrm{C}\right]$ floating at the $15 / 22 \%$ (fractions $4-5$ ) and $28 / 35 \%$ (fractions 8-9) interfaces were resolved from one another in a very reproducible fashion. Both species were clearly separated from the $42.5 \%$ sucrose cushion (fractions 12-15) containing detergent/carbonate-soluble bulk plasma membrane proteins that are not associated with low-buoyant-density material. Consequently, the protein patterns differed drastically between fractions 4-5/8-9 and 12-15 with the polypeptide composition of the latter being very similar to that of total purified plasma membranes. This was reflected in considerable enrichment of typical components of DIGs, caveolin-1/2, pp59 $9^{\mathrm{Lyn}}$, 5'-Nuc, Gcel, and the trypsin/NaCl/NEM-sensitive adipocyte cell-surface protein, CIR, and deprivement of typical transmembrane proteins, GLUT4, and IR $\beta$, in fractions 4-5/8-9 versus fractions $12-15$ as well as versus total purified plasma membranes (Fig. 1, identical amounts of protein analyzed; Table 1, control). However, fractions 4-5, which corresponded to the typical low-buoyant-density DIGs identified with conventional sucrose gradients, contained significantly higher amounts of these proteins than fractions 8-9 as revealed by the 5- to 10-fold higher amounts of caveolin-1/2, Gcel, 5'-Nuc, and CIR in fractions 4-5 versus 8-9 (Table 1, control). The relative abundance of $\mathrm{pp} 59^{\mathrm{Lyn}}$ did not differ significantly between the two species of DIGs. In agreement, SDS-PAGE analysis and Coomassie blue staining revealed a qualitatively similar protein pattern for fractions 4-5 and 8-9 with some striking quantitative differences (Fig. 1). Taken together, the materials contained in fractions $4-5$ and 8-9 seem to represent structurally related DIGs differing in the relative content of caveolin and other constituent components. Previous studies conducted by us and other investigators apparently did not succeed in separating complexes of higher buoyant density (here fractions 8-9) from detergent/carbonatesoluble bulk plasma membrane proteins (here fractions 12-15), which were collectively termed as non-DIG areas (35).

For further elucidation of the structural and functional relationship between the two different species 


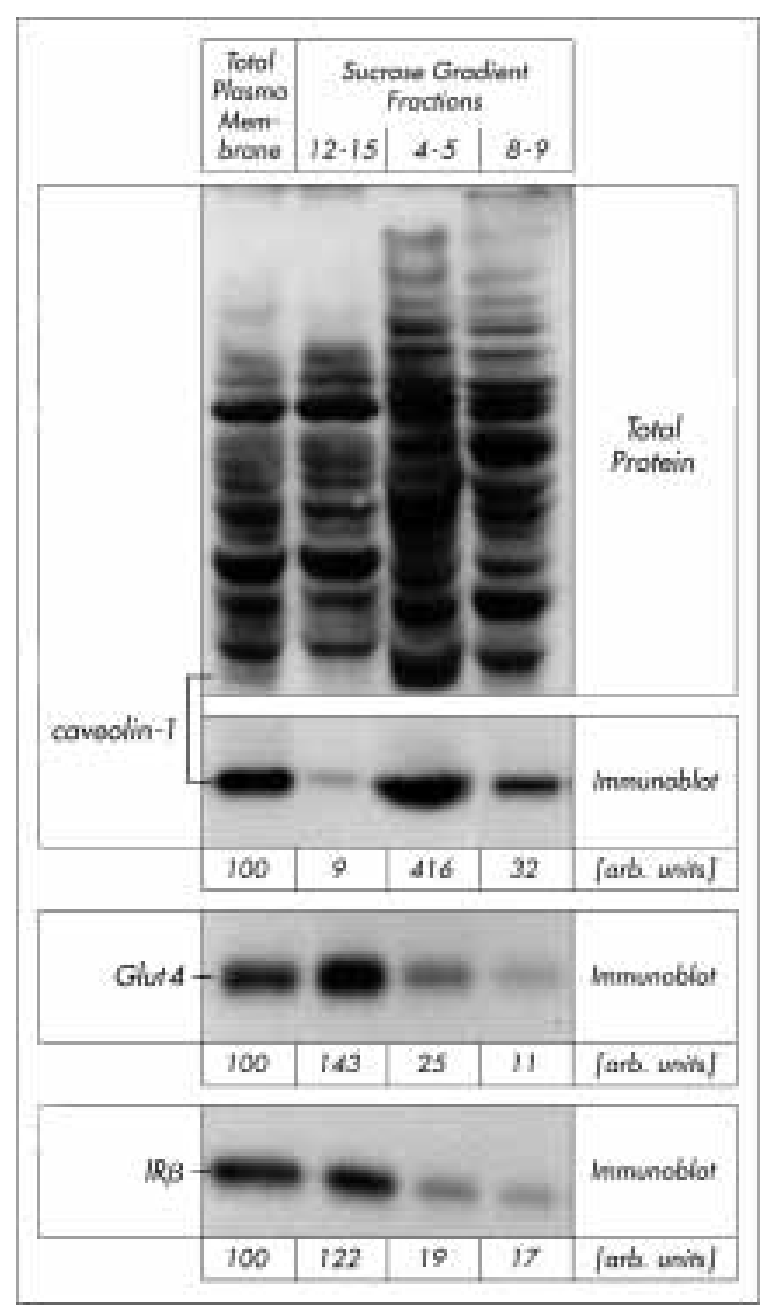

Fig. 1. Protein patterns of distinct plasma membrane microdomains. Purified plasma membranes from isolated rat adipocytes (total plasma membrane) were used for preparation of DIGs by the carbonate method and subsequent sucrose gradient density centrifugation. Pooled fractions 4 and 5 (low buoyant density, hcDIGs), fractions 8 and 9 (high buoyant density, lcDIGs), and fractions 12-15 (carbonate-soluble plasma membrane proteins) were analyzed by SDS-PAGE (identical amounts of protein) and Coomassie blue staining (total protein) or immunoblotting of caveolin-1, GLUT4, and IR $\beta$ using chemiluminescent detection. The figure shows representative photographic/chemiluminescent images repeated two times with similar results. Quantitative evaluations from three different adipocyte incubations are given as means (arbitrary units) with total plasma membranes set at 100 .

of DIGs, we destroyed their structural integrity by cholesterol extraction. $\mathrm{m} \beta \mathrm{CD}$ was found to selectively extract cholesterol from the plasma membrane in preference to other membrane lipids, thereby forming soluble inclusion complexes with cholesterol (40-42). Alternatively, reduction of plasma membrane cholesterol in intact cells can be achieved by CO treatment (20). Adipocytes were found to remain intact after extraction of up to $50 \%$ (3T3-Ll adipocytes, see ref. 20 ) or $60 \%$ (rat adipocytes, this study) of plasma membrane cholesterol. However, extraction of more than $60 \%$ of plasma membrane cholesterol by $20 \mathrm{mM} \mathrm{m} \beta \mathrm{CD}$ made rat adipocytes very sensitive for lysis toward mechanical stress and prevented the preparation of DIGs presumably due to their complete rupture and distribution of their constituent components within the bulk plasma membrane (data not shown). Two- and 10-mM $\mathrm{m} \beta C D$ caused up to $60 \%$ loss of plasma membrane cholesterol (see below) and almost complete disappearance of caveolar invaginations and/or their conversion into minor irregular structures at the adipocyte membrane surface. These structures presumably reflect flattened caveolar patches or condensed, structurally altered DIGs remaining in the membrane after extensive but partial cholesterol depletion of rat adipocytes (data not shown, see also Ref. 21). This is reminiscent of 3T3-L1 adipocytes; Stralfors et al. found that the structure of caveolae was not affected after $20 \%$, partially destroyed after $40 \%$, and almost completely destroyed after more than $50 \%$ reduction of plasma membrane cholesterol (20). At 2- and-10 $\mathrm{mM} \mathrm{m} \beta \mathrm{CD}$, we did not detect significant deprivement of caveolin-1/2, pp59 $9^{\mathrm{Lyn}}$, CIR, Gcel, and 5'-Nuc, from total DIGs as represented by fractions 4-5/8-9 and corresponding enrichment at fractions 12-15 compared to control adipocytes (Table 1). The moderate but variable amounts of IR $\beta$ and GLUT4, which can be recovered with total DIGs as has been reported previously $(43,44)$, were not significantly affected by $m \beta C D$ treatment. However, incubation of adipocytes with $\mathrm{m} \beta \mathrm{CD}$ led to an apparent shift in the recovery of pp59 $9^{\text {Lyn }}$, Nuc, Gcel, CIR, Ir $\beta$, and GLUT4 from fractions 4-5 to fractions 8-9 in a concentration-dependent manner without significantly affecting the relative distribution of caveolin-1/2 (Table 1).

The observed $m \beta C D$-dependent redistribution of GPI proteins and NRTKs from DIGs of typical low buoyant density to those of higher buoyant density described here for the first time strongly suggests that the former (fractions 4-5, termed in the following hcDIGs) harbor higher concentrations of cholesterol, caveolin, and lipid-modified signaling proteins than the latter (fractions 8-9, termed in the following lcDIGs). Cholesterol depletion of adipocytes independent of the use of $m \beta C D$ by incubation with $\mathrm{CO}$ confirmed the redistribution of constituent components from hcDIGs to lcDIGs under conditions that caused a $45-55 \%$ loss of plasma membrane cholesterol (Table 2, basal). The amount of pp59 $9^{\text {Lyn }}$ recovered with lcDIGs was increased to a comparable extent as observed after $\mathrm{m} \beta \mathrm{CD}$ treatment (Table 1). In conclusion, lcDIGs appear to be expressed (in low number) in (unstimulated) adipocytes, but their number or complex formation with constituent components increases substantially upon cholesterol depletion. Subsequently, we studied whether the observed dynamics between hcDIGs and lcDIGs is a consequence of artificial cholesterol depletion only, or if it plays a role in transmembrane signaling, a 
Table 1. Effect of cholesterol depletion on distribution of marker proteins during sucrose gradient centrifugation

\begin{tabular}{|c|c|c|c|c|c|c|c|c|c|}
\hline \multirow[b]{2}{*}{ fr. no. } & \multicolumn{3}{|c|}{ Control } & \multicolumn{3}{|c|}{$2 \mathrm{mM} \mathrm{m} \beta C D$} & \multicolumn{3}{|c|}{$10 \mathrm{mM} \mathrm{m} \beta C D$} \\
\hline & $4-5$ & 8-9 & $12-15$ & $4-5$ & 8-9 & $12-15$ & $4-5$ & $8-9$ & $12-15$ \\
\hline cav-1 & $1.00 \pm 0.03$ & $0.08 \pm 0.02$ & 0.03 & $1.13 \pm 0.27$ & $0.16 \pm 0.04$ & $0.05 \pm 0.02$ & $0.91 \pm 0.10$ & $0.19 \pm 0.07$ & $0.13 \pm 0.03$ \\
\hline cav-2 & $1.00 \pm 0.09$ & $0.11 \pm 0.04$ & $0.05 \pm 0.01$ & $1.21 \pm 0.07$ & $0.09 \pm 0.07$ & $0.07 \pm 0.02$ & $0.85 \pm 0.09$ & $0.24 \pm 0.10$ & $0.17 \pm 0.04$ \\
\hline pp59 $9^{\mathrm{Lyn}}$ & $1.00 \pm 0.12$ & $0.76 \pm 0.11$ & 0.01 & $0.89 \pm 0.06$ & $0.92 \pm 0.14$ & 0.04 & $0.20 \pm 0.09$ & $1.72 \pm 0.19$ & $0.08 \pm 0.02$ \\
\hline $5^{\prime}-\mathrm{Nuc}$ & $1.00 \pm 0.15$ & $0.13 \pm 0.04$ & $0.07 \pm 0.02$ & $0.84 \pm 0.11$ & $0.23 \pm 0.03$ & $0.03 \pm 0.02$ & $0.40 \pm 0.08$ & $0.69 \pm 0.14$ & $0.12 \pm 0.03$ \\
\hline Gcel & $1.00 \pm 0.19$ & $0.11 \pm 0.02$ & $0.04 \pm 0.01$ & $0.79 \pm 0.12$ & $0.21 \pm 0.06$ & 0.06 & $0.49 \pm 0.07$ & $0.55 \pm 0.10$ & $0.09 \pm 0.02$ \\
\hline $\operatorname{IR} \beta$ & $1.00 \pm 0.11$ & $0.89 \pm 0.10$ & $7.89 \pm 0.78$ & $0.70 \pm 0.13$ & $1.43 \pm 0.25$ & $8.33 \pm 0.92$ & $0.45 \pm 0.09$ & $1.72 \pm 0.29$ & $9.03 \pm 0.85$ \\
\hline GLUT4 & $1.00 \pm 0.19$ & $0.54 \pm 0.08$ & $8.72 \pm 1.11$ & $0.92 \pm 0.15$ & $1.05 \pm 0.18$ & $9.44 \pm 1.06$ & $0.66 \pm 0.08$ & $2.03 \pm 0.39$ & $10.27 \pm 1.54$ \\
\hline CIR & $1.00 \pm 0.14$ & $0.24 \pm 0.09$ & 0.02 & $0.54 \pm 0.06$ & $0.32 \pm 0.11$ & 0.01 & $0.22 \pm 0.11$ & $0.81 \pm 0.13$ & $0.06 \pm 0.01$ \\
\hline
\end{tabular}

Isolated rat adipocytes were incubated $\left(50 \mathrm{~min}, 30^{\circ} \mathrm{C}\right)$ in the absence or presence of $\mathrm{m} \beta \mathrm{CD}$. DIGs were prepared and subjected to sucrose gradient centrifugation. Fractions 4-5, 8-9, and 12-15 were immunoblotted for caveolin-1/2 (cav-1/2), pp59 $9^{\mathrm{Lyn}}$, IR $\beta$ and GLUT4, assayed for 5'-nucleotidase (5'-Nuc) enzymic activity, photoaffinity labeled for Gcel, and labeled with $N$-ethyl $\left[2,3-{ }^{14} \mathrm{C}\right]$ maleimide for CIR. Quantitative evaluations (chemi- and phosphorimages, enzymatic assay) represent the mean \pm SD of three to four independent adipocyte preparations with incubations in triplicate each (fractions 4-5 in the absence of $m \beta C D$ set at 1 ). The total amount of each protein recovered in the three fraction pools of $m \beta C D$-treated adipocytes was $88-113 \%(2 \mathrm{mM})$ and $81-93 \%(10 \mathrm{mM})$ of that of untreated cells.

function previously attributed to (hc)DIGs/caveolae $(12,13,34,45)$.

\section{PIG41 and Glimepiride Trigger the Redistribution of Signaling Components from hcDIGs to lcDIGs}

Our previous studies demonstrated the stimulusdependent translocation of lipid-modified signaling components from DIGs to so-called non-DIG areas of the adipocyte plasma membrane (35), but left open the possibility of uniform distribution of the released proteins across the bulk plasma membrane or of their accumulation at plasma membrane microdomains different from hcDIGs. In the following, we studied the possibility of lcDIGs operating as target for GPI proteins and NRTKs upon their release from hcDIGs in response to insulinmimetic stimuli, as is the case upon cholesterol depletion. Consequently, we investigated the distribution of pp59 $9^{\mathrm{Lyn}}$, Gcel, and caveolin-1 between hcDIGs and lcDIGs in response to PIG4l and glimepiride in control and cholesterol-depleted adipocytes. Treatment of control cells with both PIG4l and glimepiride at maximally effective concentrations reduced the amounts of Gcel and pp $59^{\mathrm{Lyn}}$ recovered with hcDIGs by about $55-70 \%$ and $40-55 \%$, respectively, and concomitantly increased their abundance at lcDIGs by about 2.7- to 4.6-fold and 3.4- to 4.9-fold, respectively (Fig. 2). The relative distribution of caveolin-1 between hcDIGs and lcDIGs was not altered by PIG4l and glimepiride compatible with a role of this caveolin as a structural component for both types of DIGs. The identity of lcDIGs, the formation of which is promoted by PIG41/glimepiride treatment and cholesterol depletion, was tested by sequential incubation of rat adipocytes with $\mathrm{m} \beta \mathrm{CD}$ and PIG4l or glime- piride (Fig. 2). In $\mathrm{m} \beta \mathrm{CD}$-treated adipocytes, the amounts of Gcel and pp59 $9^{\mathrm{Lyn}}$ in lcDIGs in the basal state was elevated by 2.4- to 3.5-fold compared to control cells and increased further by 1.5 - to 2 -fold upon challenge with either PIG4l or glimepiride. Thus, the incremental increase in stimulus-dependent redistribution was diminished by $50-60 \%$ by cholesterol depletion, demonstrating less than additive effects of PIG4l/glimepiride and cholesterol depletion. This was confirmed by the subadditive gain in the amount of pp59 $9^{\mathrm{Lyn}}$ located at lcDIGs, which is elicited by cholesterol oxidation in combination with PIG41 or glimepiride (Table 2, $\mathrm{CO})$. A closer inspection of the sucrose gradients loaded with carbonate-extracted plasma membranes from cholesterol-depleted adipocytes versus PIG41or glimepiride-treated control adipocytes versus PIG41 - or glimepiride-treated cholesterol-depleted adipocytes did not reveal any significant differences in the relative position (fraction number) and physical appearance (e.g., sharpness) of the bands or the emergence of additional bands not identical with lc/hcDIGs (data not shown). Taken together, cholesterol depletion and certain insulin-mimetic stimuli seem to trigger the translocation of (a subset of) lipid-modified signaling components from hcDIGs to the same plasma membrane microdomains, the lcDIGs.

\section{Cholesterol Depletion of Adipocytes Disrupts the DIGs-Caveolin-pp59Lyn Pathway to IRS-1}

We next investigated the putative consequences of the observed translocation of GPI proteins and NRTKs from hcDIGs to lcDIGs in response to cholesterol depletion and/or insulin-mimetic stimuli on their release from hcDIG-associated caveolin and 


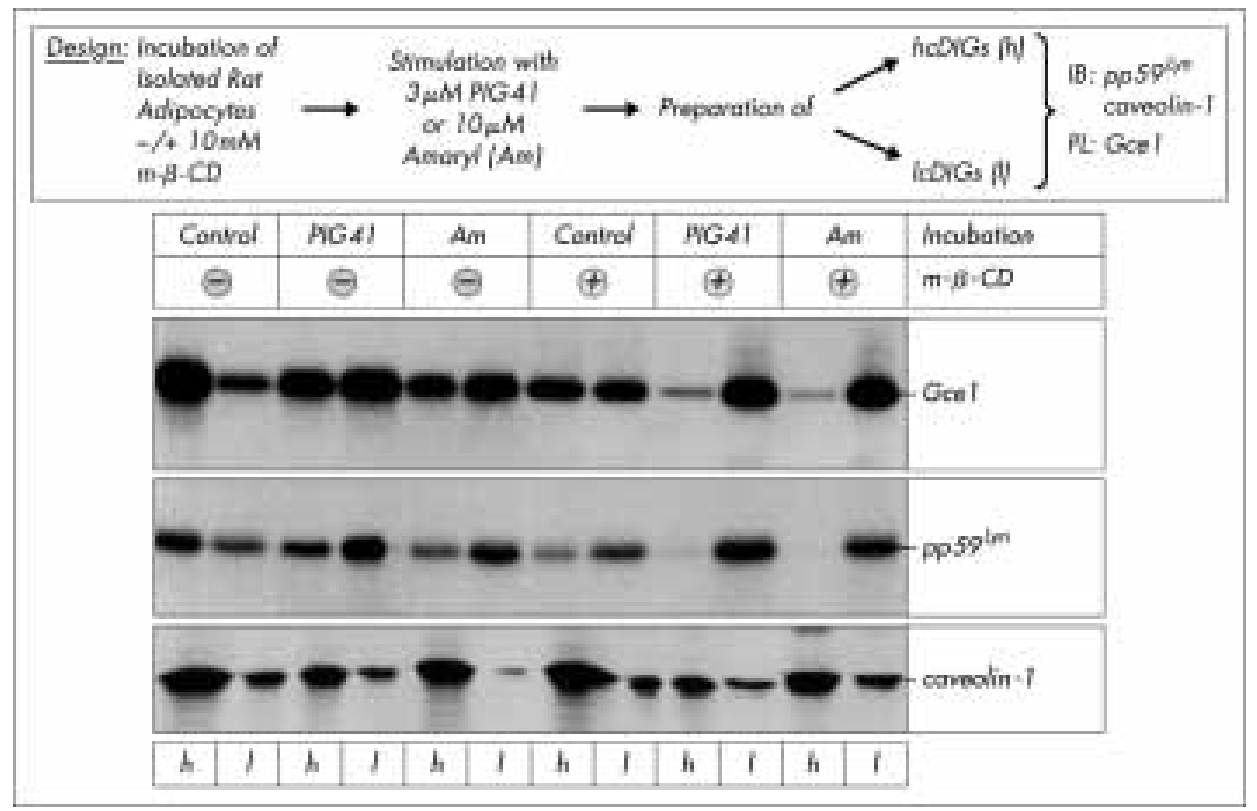

Fig. 2. Effect of cholesterol depletion on translocation of Gcel and pp59 ${ }^{\mathrm{Lyn}}$ from hcDIGs to lcDIGs. Isolated rat adipocytes were incubated in the absence or presence of $10 \mathrm{mM} \mathrm{m} \beta \mathrm{CD}\left(50 \mathrm{~min}, 30^{\circ} \mathrm{C}\right)$ and subsequently in the absence (control) or presence of $3 \mu \mathrm{M}$ PIG4l or $30 \mu \mathrm{M}$ glimepiride (Am). hcDIGs (h) and lcDIGs (l) were prepared and immunoblotted for pp59 ${ }^{\mathrm{Lyn}}$ and caveolin-l (IB) or photoaffinity labeled for Gcel (PL). The figure shows representative phosphor- and chemiluminescent images repeated three times.

activation. Identical amounts of caveolin immunoprecipitates (as confirmed by homologous caveolin immunoblotting) were used for the immunoblot analyses of caveolin-associated signaling proteins from nondissociated hcDIGs of $\mathrm{m} \beta C D$-treated and control adipocytes that have been challenged with
PIG41, glimepiride, or CBDP. In control cells, PIG41 and glimepiride triggered efficient dissociation from caveolin of Gcel, pp59 $9^{\mathrm{Lyn}}$ and $\mathrm{pp} 125^{\mathrm{Fak}}$ as well as tyrosine phosphorylation of pp59 $9^{\mathrm{Lyn}}$ (Fig. 3). At $10 \mathrm{mM} \mathrm{m} \beta \mathrm{CD}$, PIG4l and glimepiride (Fig. 3) as well as CBDP (Fig. 4) at maximally effective concentrations

Table 2. Effect of CO treatment and withdrawal on pp59 $59^{\text {Lyn }}$ translocation and IRS-1 tyrosine phosphorylation

\begin{tabular}{|c|c|c|c|c|c|c|}
\hline & \multicolumn{3}{|c|}{ pp59 ${ }^{\text {Lyn }}$ Translocation to lcDIGs } & \multicolumn{3}{|c|}{ IRS-1 Tyrosine Phosphorylation } \\
\hline & Control & $+\mathrm{CO}$ & $\begin{array}{c}+\mathrm{CO}>-\mathrm{CO} \\
180 \mathrm{~min}\end{array}$ & Control & $+\mathrm{CO}$ & $\begin{array}{c}+\mathrm{CO}>-\mathrm{CO} \\
120 \mathrm{~min}\end{array}$ \\
\hline Basal & $1.0 \pm 0.2$ & $3.7 \pm 0.5$ & $1.5 \pm 0.2$ & $1.0 \pm 0.1$ & $1.1 \pm 0.2$ & $0.9 \pm 0.1$ \\
\hline $\mathrm{Na}_{3} \mathrm{VO}_{4}$ & $1.3 \pm 0.3$ & $3.5 \pm 0.4$ & $1.4 \pm 0.2$ & $10.6 \pm 1.1$ & $9.8 \pm 1.3$ & $10.5 \pm 1.0$ \\
\hline Insulin & $1.2 \pm 0.3$ & $3.1 \pm 0.4$ & $1.8 \pm 0.2$ & $16.2 \pm 2.1$ & $7.9 \pm 0.9$ & $14.8 \pm 1.7$ \\
\hline PIG41 & $4.4 \pm 0.5$ & $6.9 \pm 0.8$ & $4.5 \pm 0.6$ & $15.3 \pm 1.9$ & $5.2 \pm 0.6$ & $16.7 \pm 1.9$ \\
\hline CBDP & $3.3 \pm 0.4$ & $7.1 \pm 0.8$ & $3.8 \pm 0.4$ & $4.9 \pm 0.6$ & $1.6 \pm 0.2$ & $4.5 \pm 0.6$ \\
\hline Glim & $3.1 \pm 0.4$ & $5.5 \pm 0.7$ & $2.9 \pm 0.4$ & $6.6 \pm 0.8$ & $2.2 \pm 0.3$ & $6.9 \pm 1.0$ \\
\hline Trypsin/NaCl & $2.5 \pm 0.4$ & $6.3 \pm 0.7$ & $3.0 \pm 0.4$ & $4.2 \pm 0.5$ & $1.4 \pm 0.3$ & $4.5 \pm 0.5$ \\
\hline NEM & $2.2 \pm 0.4$ & $5.0 \pm 0.4$ & $2.4 \pm 0.3$ & $5.2 \pm 0.8$ & $1.9 \pm 0.3$ & $4.6 \pm 0.6$ \\
\hline
\end{tabular}

Isolated rat adipocytes were incubated $\left(75 \mathrm{~min}, 37^{\circ} \mathrm{C}\right)$ in the absence (control) or presence of $1.5 \mathrm{U} / \mathrm{ml}$ cholesterol oxidase $(\mathrm{CO})$. Subsequently, portions of the CO-treated cells were washed by flotation and then incubated for the periods indicated. Thereafter, the adipocytes were incubated $\left(15 \mathrm{~min}, 37^{\circ} \mathrm{C}\right)$ with $1 \mathrm{mM} \mathrm{Na}_{3} \mathrm{VO}_{4}, 5 \mathrm{nM}$ insulin, $3 \mu \mathrm{M}$ PIG41, or $10 \mu \mathrm{M}$ glimepiride or electroporated in the presence of $300 \mu \mathrm{M}$ caveolin-binding domain peptide (CBDP) or treated with trypsin plus NaCl or NEM. lcDIGs were prepared and immunoblotted for pp59 $9^{\mathrm{Lyn}}$. IRS-1 was immunoprecipitated from lcDIGs and immunoblotted for tyrosine phosphorylation. Fold stimulations are given with basal values (absence of insulin) obtained with control cells set at 1 . Each value represents the mean \pm SD of two independent adipocyte preparations with incubations in triplicate each. 


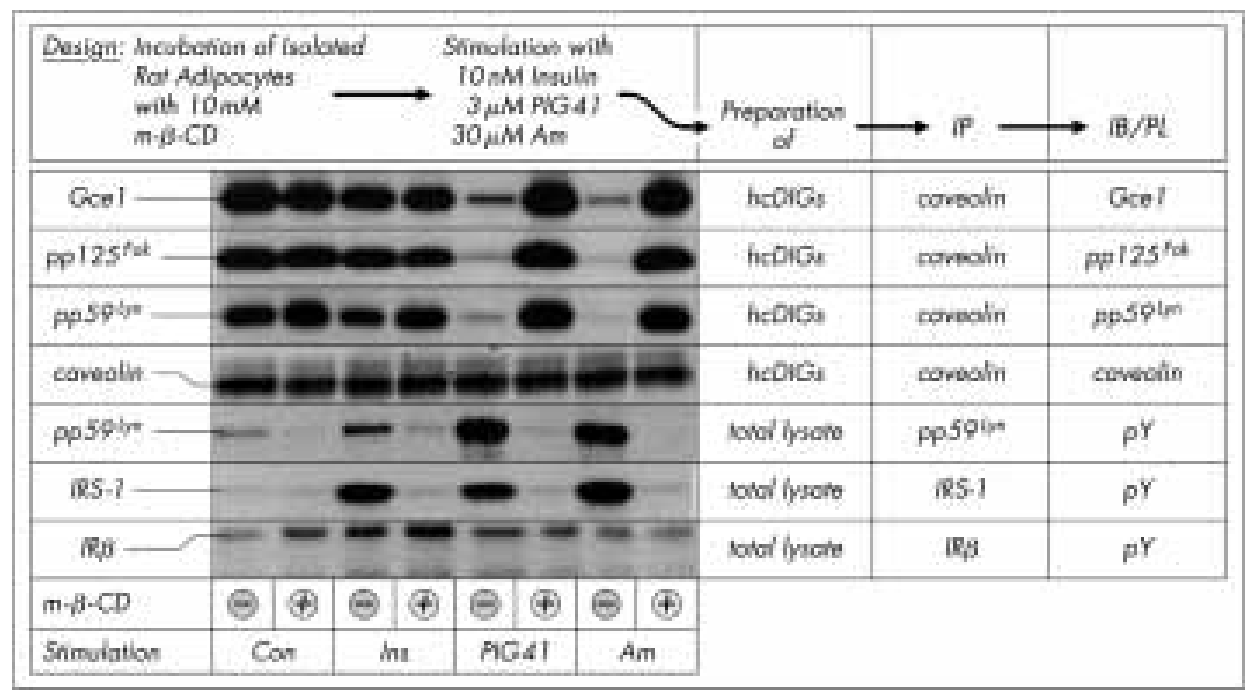

Fig. 3. Effect of cholesterol depletion on PIG41- and glimepiride-induced redistribution and activation of signaling components. Isolated rat adipocytes were incubated in the absence or presence of $10 \mathrm{mM} \mathrm{m} \beta \mathrm{CD}\left(50 \mathrm{~min}, 30^{\circ} \mathrm{C}\right)$ and subsequently without (Con) or with $10 \mathrm{nM}$ insulin (Ins), $3 \mu \mathrm{M}$ PIG41, or $30 \mu \mathrm{M}$ glimepiride (Am) $\left(15 \mathrm{~min}, 37^{\circ} \mathrm{C}\right)$. hcDIGs were prepared and used for immunoprecipitation (IP) of caveolin-1 in nondissociating buffer. The immunoprecipitates were immunoblotted (IB) for pp125 ${ }^{\mathrm{Fak}}, \mathrm{pp5}^{\mathrm{Lyn}}$, and caveolin-1, and photoaffinity labeled for Gcel (PL). From total cell lysates, pp59 ${ }^{\mathrm{Lyn}}$, IRS-1, and IR $\beta$ were immunoprecipitated and then immunoblotted for phosphotyrosine (pY). Representative phosphor/chemiluminescent images repeated three times with similar results are shown.

completely failed either to reduce the amount of caveolin-associated Gcel, pp $125^{\mathrm{Fak}}$, and $\mathrm{pp} 59^{\mathrm{Ly}}$ in hcDIGs or to induce tyrosine phosphorylation of pp59 $9^{\text {Ly }}$ and IRS-1. The higher plasma membrane cholesterol levels left in the presence of 2 and $5 \mathrm{mM}$ $\mathrm{m} \beta \mathrm{CD}$ correlated well with less-pronounced inhi- bition of PIG41-, glimepiride-, and CBDP-induced dissociation of Gcel and pp59 $9^{\mathrm{Lyn}}$ from caveolin and tyrosine phosphorylation of pp59 $9^{\mathrm{Lyn}}$. The $\mathrm{m} \beta \mathrm{CD}$ dependent decline in plasma membrane cholesterol was paralleled by interference with stimulusinduced IRS-1 tyrosine phosphorylation and glucose

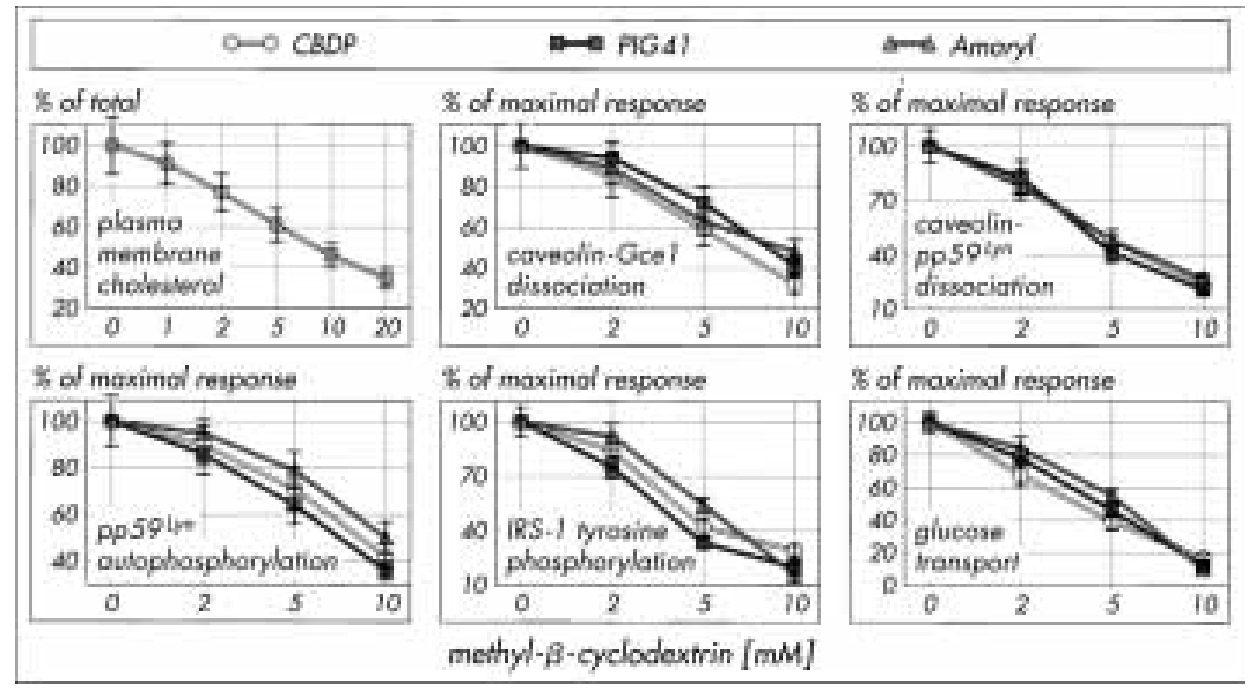

Fig. 4. Effect of cholesterol depletion on redistribution of signaling proteins, insulin-mimetic signaling, and glucose transport activation by various stimuli. Isolated rat adipocytes were incubated in the absence or presence of increasing concentrations of $\mathrm{m} \beta \mathrm{CD}\left(50 \mathrm{~min}, 30^{\circ} \mathrm{C}\right)$ prior to subsequent treatment with $3 \mu \mathrm{M}$ PIG41, $30 \mu \mathrm{M}$ glimepiride, or $300 \mu \mathrm{M}$ CBDP. Purified plasma membranes were analyzed for cholesterol (set at $100 \%=0.27 \pm 0.07 \mathrm{nmol} / \mu \mathrm{g}$ protein in the absence of $\mathrm{m} \beta \mathrm{CD}$ ). hcDIGs were prepared and used for immunoprecipitation of caveolin- 1 in nondissociating buffer. The immunoprecipitates were photoaffinity labeled for Gcel (dissociation of caveolin-Gcel interaction) and immunoblotted for pp59 ${ }^{\mathrm{Lyn}}$ (dissociation of caveolin-pp59 ${ }^{\mathrm{Lyn}}$ interaction). From total cell lysates, pp59 ${ }^{\mathrm{Lyn}}$ and IRS-1 were immunoprecipitated and then immunoblotted for phosphotyrosine (pp59 $9^{\mathrm{Lyn}}$ and IRS-1 tyrosine phosphorylation). Glucose transport was determined in addition. Each value represents the mean \pm SD from three independent adipocyte incubations with determinations in quadruplicate each (absence of $\mathrm{m} \beta \mathrm{CD}$ set at $100 \%$ each). 
transport activation (Fig. 4). These findings demonstrate the involvement of hcDIGs in insulinmimetic metabolic signaling and action by PIG41, glimepiride, and CBDP. The $\mathrm{m} \beta \mathrm{CD}$-blockade of the release of pp59 $9^{\mathrm{Lyn}}$ from hcDIGs-associated caveolin triggered by excess of intracellular pp5 $9^{\mathrm{Ly}}$-derived CBDP (by direct competition with the caveolin scaffolding domain of caveolin; see ref. 30) suggests that cholesterol depletion abrogates insulinmimetic signaling by PIG41, glimepiride, and CBDP through interference with or downstream of the interaction between caveolin and signaling proteins. Interestingly, tyrosine phosphorylation of IRS- 1 and pp59 $9^{\mathrm{Lyn}}$ in response to insulin was also almost completely eliminated in $\mathrm{m} \beta \mathrm{CD}$-treated $(10 \mathrm{mM})$ adipocytes, although autophosphorylation of IR $\beta$ was not significantly affected (Fig. 3). This is in agreement with recent findings of Stralfors et al. (21). Because pp59 $9^{\mathrm{Ly}}$ is apparently not involved in insulin signaling to the glucose transport system (31), direct coupling of the IR to downstream signaling components such as IRS-1 may require structural integrity of hcDIGs or high plasma membrane cholesterol content per se explaining blockade of IRS-1 tyrosine phosphorylation despite activation of $\operatorname{IR} \beta$ in cholesterol-depleted adipocytes.

Next we studied the putative interference of cholesterol depletion with other insulin-mimetic stimuli, which either depend on activation of $\operatorname{IR} \beta$ in case of vanadium compounds, such as $\mathrm{Na}_{3} \mathrm{VO}_{4}$, and its more potent analog POV (by apparent inhibition of IR $\beta$ dephosphorylation; see ref. 46) or act independent of IR $\beta$ in case of inactivation of CIR (by trypsin/NaCl-or NEM-treatment; see ref. 33).
Tyrosine phosphorylation of IRS-1 was decreased by $60-75 \%$ in cholesterol-depleted (by both $\mathrm{m} \beta \mathrm{CD}$ and $\mathrm{CO}$ ) versus control rat adipocytes in response to maximally effective concentrations of insulin, PIG41, CBDP, or glimepiride (as expected) and inactivation of CIR (Fig. 5). In contrast, cholesterol depletion did not significantly impair tyrosine phosphorylation of IRS-1 (and IR $\beta$ ) upon challenge with $1 \mathrm{mM} \mathrm{Na} \mathrm{VO}_{4}$ or $5 \mu \mathrm{M}$ POV (Fig. 5; Tables 2 and 3, CO). These data confirm the prevalent view that vanadium compounds induce IRS-1 tyrosine phosphorylation through activation of IR $\beta$ rather than pp59 $9^{\mathrm{LY} n}$. However, the molecular basis for the surprising differential susceptibility of insulin- and vanadate-dependent IRS-1 tyrosine phosphorylation toward cholesterol depletion remains unclear, but obviously cannot rely solely on impairment of the interaction between the activated IR and IRS-1.

The observed interference of $\mathrm{m} \beta \mathrm{CD}$ with structure and function of hcDIGs may be due to indirect and unspecific effects rather than cholesterol depletion. To exclude this possibility, we compared the effect of $\mathrm{m} \beta \mathrm{CD}$ alone or complexed to cholesterol (which is in rapid equilibrium to the adipocyte plasma membrane-bound cholesterol via formation of a new cholesterol-containing pool in the aqueous phase) on IRS-1 tyrosine phosphorylation and lipogenesis in rat adipocytes challenged with the insulin-mimetic stimuli (Table 3). Consequently, treatment with $\mathrm{m} \beta \mathrm{CD}$-cholesterol complex exposed the adipocytes to the same concentration of $m \beta C D$ as that to which the cholesterol-depleted cells were exposed but left the cholesterol levels unchanged or

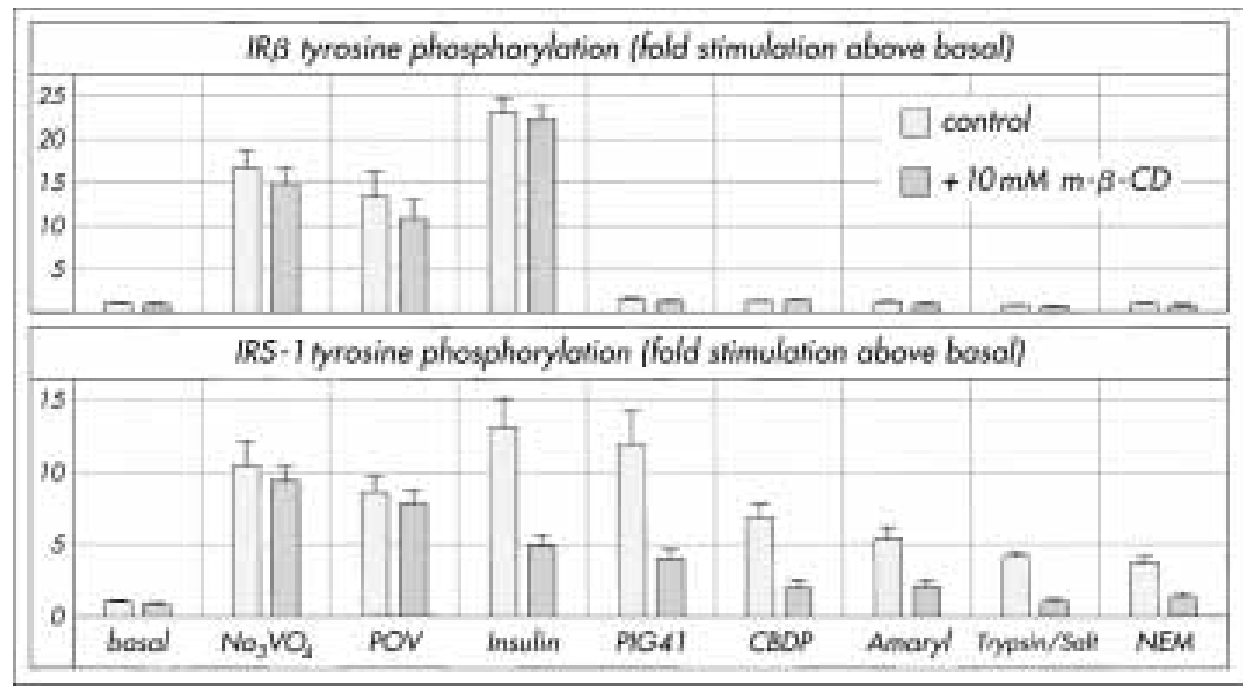

Fig. 5. Effect of cholesterol depletion on stimulus-dependent IR $\beta$ and IRS-1 tyrosine phosphorylation. Isolated rat adipocytes were incubated in the absence (open bars) or presence (filled bars) of $10 \mathrm{mM} \mathrm{m} \beta \mathrm{CD}\left(50 \mathrm{~min}, 30^{\circ} \mathrm{C}\right)$ and subsequently without (basal) or with $1 \mathrm{mM} \mathrm{Na} \mathrm{VO}_{4}, 10 \mu \mathrm{M}$ POV, $10 \mathrm{nM}$ insulin, $3 \mu \mathrm{M}$ PIG4l, $300 \mu \mathrm{M}$ CBDP, $30 \mu \mathrm{M}$ glimepiride, $10 \mu \mathrm{g} / \mathrm{ml}$ trypsin plus $0.5 \mathrm{M}$ $\mathrm{NaCl}$, or $1 \mathrm{mM}$ NEM. From total cell lysates, IR $\beta$ and IRS-1 were immunoprecipitated and then immunoblotted for phosphotyrosine. Each value represents the mean \pm SD from three to five independent adipocyte incubations with immunoblotting in triplicate each (set at 1 for basal cells in the absence of $\mathrm{m} \beta \mathrm{CD}$ ). 
Table 3. Specificity and reversibility of $\mathrm{m} \beta C D$ treatment on insulin-mimetic signaling and action

\begin{tabular}{|c|c|c|c|c|c|c|c|c|}
\hline & \multicolumn{4}{|c|}{ IRS-1 Tyrosine Phosphorylation } & \multicolumn{4}{|c|}{ Lipogenesis } \\
\hline & Control & $\mathbf{m} \beta C D$ & $\begin{array}{c}\mathbf{m} \beta C D+ \\
\mathbf{m} \beta C D-c h o l\end{array}$ & $\underset{\mathbf{m} \beta C D-c h o l}{\operatorname{m} \beta C D}>$ & Control & $\mathbf{m} \beta C D$ & $\begin{array}{c}\mathbf{m} \beta C D+ \\
\mathbf{m} \beta C D-c h o l\end{array}$ & $\begin{array}{c}\mathrm{m} \beta C D> \\
\mathrm{m} \beta C D-c h o l\end{array}$ \\
\hline Basal & $1.0 \pm 0.2$ & $0.8 \pm 0.2$ & $1.1 \pm 0.2$ & $0.9 \pm 0.1$ & $1.0 \pm 0.1$ & $0.9 \pm 0.2$ & $1.3 \pm 0.2$ & $0.8 \pm 0.1$ \\
\hline $\mathrm{Na}_{3} \mathrm{VO}_{4}$ & $11.2 \pm 2.3$ & $10.6 \pm 2.4$ & $12.3 \pm 1.9$ & $10.2 \pm 1.9$ & $18.6 \pm 1.4$ & $16.4 \pm 1.5$ & $19.8 \pm 2.3$ & $15.5 \pm 1.9$ \\
\hline Insulin & $14.6 \pm 3.2$ & $5.3 \pm 1.2$ & $12.0 \pm 1.5$ & $10.6 \pm 1.1$ & $25.8 \pm 1.7$ & $7.9 \pm 0.9$ & $21.3 \pm 1.8$ & $16.9 \pm 1.4$ \\
\hline PIG41 & $13.9 \pm 2.1$ & $4.6 \pm 1.4$ & $11.5 \pm 2.3$ & $8.9 \pm 1.7$ & $22.5 \pm 2.0$ & $6.0 \pm 0.7$ & $18.7 \pm 1.9$ & $14.6 \pm 1.7$ \\
\hline CBDP & $6.1 \pm 1.1$ & $1.5 \pm 0.3$ & $4.9 \pm 0.7$ & $3.5 \pm 0.5$ & $13.1 \pm 1.8$ & $4.9 \pm 0.6$ & $10.4 \pm 1.3$ & $8.3 \pm 0.7$ \\
\hline Glim & $5.2 \pm 0.8$ & $1.7 \pm 0.4$ & $4.1 \pm 0.6$ & $3.6 \pm 0.5$ & $8.3 \pm 1.1$ & $2.8 \pm 0.4$ & $7.7 \pm 1.1$ & $6.1 \pm 0.8$ \\
\hline $\begin{array}{l}\text { Trypsin/ } \\
\text { NaCI }\end{array}$ & $4.5 \pm 0.6$ & $1.1 \pm 0.2$ & $3.4 \pm 0.5$ & $2.8 \pm 0.3$ & $6.7 \pm 0.9$ & $1.5 \pm 0.2$ & $5.1 \pm 0.6$ & $4.0 \pm 0.6$ \\
\hline NEM & $4.8 \pm 0.7$ & $1.6 \pm 0.2$ & $3.9 \pm 0.6$ & $3.1 \pm 0.2$ & $7.5 \pm 0.9$ & $2.6 \pm 0.3$ & $5.9 \pm 0.5$ & $5.1 \pm 0.6$ \\
\hline
\end{tabular}

Isolated rat adipocytes were incubated $\left(50 \mathrm{~min}, 30^{\circ} \mathrm{C}\right)$ in the absence (control) or presence of $3.8 \mathrm{mM} \mathrm{m} \beta \mathrm{CD}$ or $1.9 \mathrm{mM} \mathrm{m} \beta \mathrm{CD}$ plus $1.9 \mathrm{mM} \mathrm{m} \beta \mathrm{CD}$-cholesterol complex $(\mathrm{m} \beta \mathrm{CD}+\mathrm{m} \beta \mathrm{CD}$-chol). Alternatively, the adipocytes were first incubated in the presence of $3.8 \mathrm{mM} \mathrm{m} \beta \mathrm{CD}$, then washed four times by flotation, and finally incubated $\left(50 \mathrm{~min}, 30^{\circ} \mathrm{C}\right)$ at the intial cell titer in the presence of $3.8 \mathrm{mM} \mathrm{m} \beta C D$-chol $\left(\mathrm{m} \beta C D>\mathrm{m} \beta C D\right.$-chol). Thereafter, the adipocytes were incubated $\left(15 \mathrm{~min}, 37^{\circ} \mathrm{C}\right) \mathrm{with} \mathrm{mmM} \mathrm{Na} \mathrm{VO}_{4}, 5 \mathrm{nM}$ insulin, $3 \mu \mathrm{M}$ PIG41, or $10 \mu \mathrm{M}$ glimepiride; or electroporated in the presence of $300 \mu \mathrm{M}$ CBDP; or treated with trypsin plus NaCl or NEM. IRS- 1 was immunoprecipitated and immunoblotted for phosphotyrosine. Lipogenesis was measured in addition. Fold stimulations are given with basal values (absence of insulin) obtained with control cells set at 1 . Each value represents the mean \pm SD of three independent adipocyte preparations with incubations in triplicate each.

even slightly elevated as compared with control cells not incubated with $\mathrm{m} \beta \mathrm{CD}$ (data not shown). IRS-1 tyrosine phosphorylation and lipogenesis (one of the most sensitive parameters for metabolic insulin action in isolated rat adipocytes) in response to insulin, PIG41, glimepiride, CBDP, or inactivation of CIR were reduced by $50-70 \%$ in adipocytes exposed to $\mathrm{m} \beta \mathrm{CD}$ alone, but not significantly affected in the simultaneous $(\mathrm{m} \beta \mathrm{CD}+\mathrm{m} \beta \mathrm{CD}$-chol) or sequential $(\mathrm{m} \beta \mathrm{CD}>\mathrm{m} \beta \mathrm{CD}$-chol) presence of $\mathrm{m} \beta \mathrm{CD}$ and $\mathrm{m} \beta \mathrm{CD}$ complexed to cholesterol as compared with control cells (Table 3). Furthermore, spontaneous transfer of cholesterol from the $m \beta C D$ cholesterol complexes to cholesterol-depleted (by $\mathrm{m} \beta \mathrm{CD}$ ) adipocytes $(\mathrm{m} \beta \mathrm{CD}>\mathrm{m} \beta \mathrm{CD}$-chol) was accompanied by restoration of stimulation of both IRS-1 tyrosine phosphorylation and lipogenesis to $50-70 \%$ of that of control cells (Table 3). Similarly, the time-dependent replenishment of plasma membrane cholesterol in course of incubation of cholesterol-depleted (by $\mathrm{CO}$ ) adipocytes during subsequent absence of $\mathrm{CO}$ resulted in regain of stimulus-dependent IRS-1 tyrosine phosphorylation to $70-95 \%$ of that of control cells (Table 2 ). The potent increase in IRS-1 tyrosine phosphorylation and lipogenesis provoked by $\mathrm{Na}_{3} \mathrm{VO}_{4}$ was not reduced in adipocytes exposed to $\mathrm{m} \beta \mathrm{CD}$ alone, $\mathrm{m} \beta \mathrm{CD}$ complexed to cholesterol, or CO. Taken together, these results strongly argue that the $\mathrm{m} \beta \mathrm{CD}$-/CO-induced translocation of GPI proteins and NRTKs from hcDIGs to lcDIGs and the resulting inhibition of the
DIGs-caveolin-pp59 $9^{\text {Lyn }}$-IRS-1 pathway are caused by cholesterol depletion and not by the presence of $\mathrm{m} \beta C D$ or $C O$ per se. In addition, the retranslocation of GPI proteins and NRTKs from hcDIGs to lcDIGs and the concomitant restoration of the DIGs-caveolinpp $59^{\mathrm{Lyn}}$-IRS-1 pathway upon replenishment of plasma membrane cholesterol are not compatible with irreversible structural alterations in the adipocyte plasma membrane caused by $\mathrm{m} \beta \mathrm{CD}$ or $\mathrm{CO}$ action.

\section{CIR-Dependent Redistribution of hcDIG-Associated Components is Blocked by Cholesterol Depletion}

CIR has recently been shown to be involved in (PIG-dependent) redistribution of signaling components from DIGs to non-DIG areas of the adipocyte plasma membrane $(22,33)$. Now we investigated the impact of inactivation of CIR on the translocation of NRTKs from hcDIGs to lcDIGs and its relationship to the corresponding effect of cholesterol depletion. First, the association of NRTKs with caveolin residing in hcDIGs in basal and PIG4l-stimulated adipocytes upon inactivation of CIR was studied (Fig. 6). In basal rat adipocytes with CIR inactivated by treatment with trypsin/ $\mathrm{NaCl}$ or NEM, the amounts of pp59 $9^{\mathrm{Lyn}}$ and $\mathrm{pp} 125^{\mathrm{Fak}}$ that were coimmunoprecipitated with caveolin from hcDIGs were reduced by $65-75 \%$ and $35-45 \%$, respectively (Fig. 6A and $B$ ). In adipocytes reconstituted with trypsin/ $\mathrm{NaCl}$ extract containing CIR, the amount of caveolinassociated $\mathrm{pp} 59^{\mathrm{Lyn}}$ and pp $125^{\mathrm{Fak}}$ in hcDIGs approached control levels. Challenge of trypsin/ $\mathrm{NaCl}-$ or 

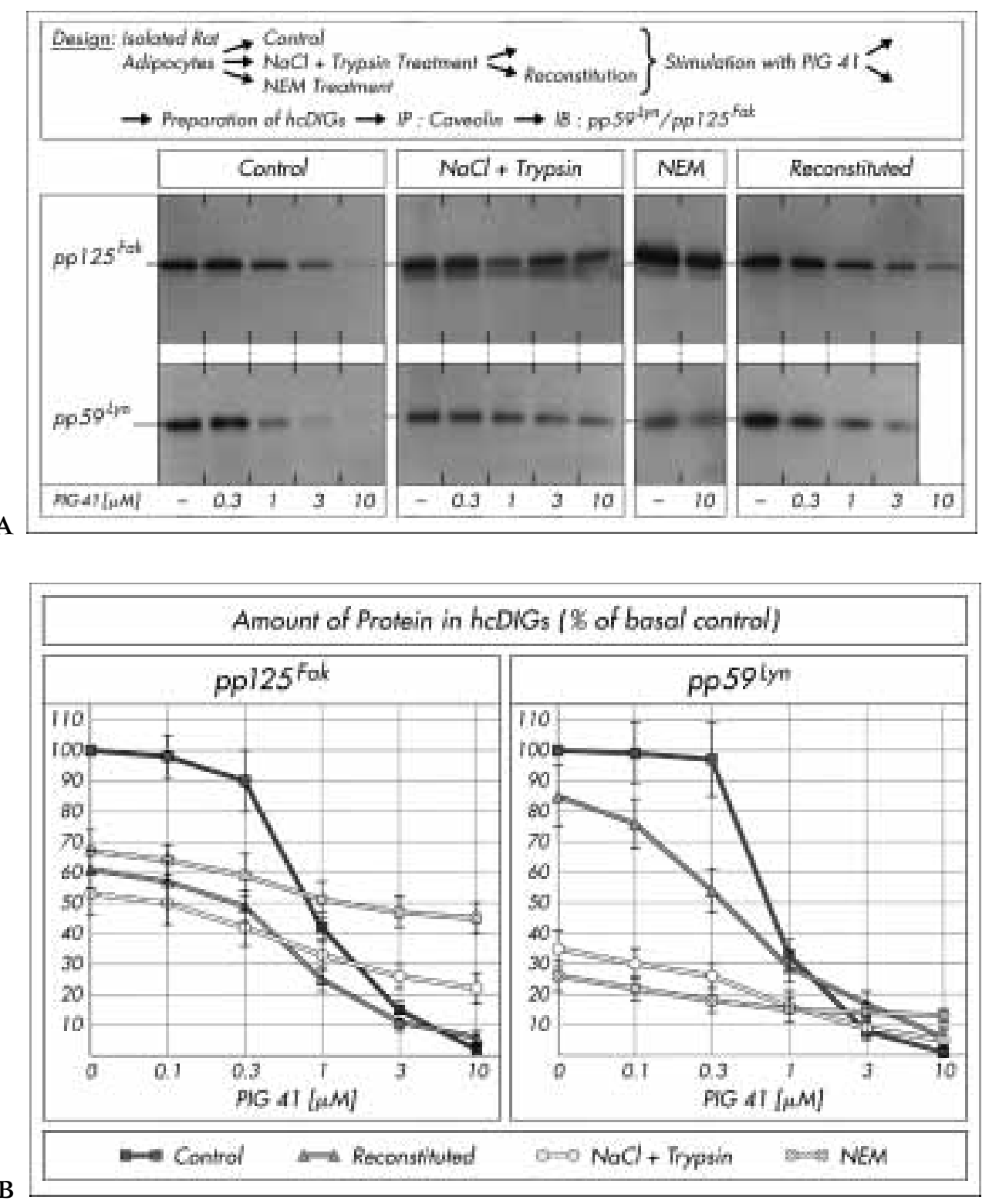

Fig. 6. Effect of cholesterol depletion on CIR-dependent dissociation of pp125 $5^{\mathrm{Fak}}$ and pp59 ${ }^{\mathrm{Lyn}}$ from caveolin. Isolated rat adipocytes were incubated (see Materials and Methods) in the absence (Control) or presence of $10 \mu \mathrm{g} / \mathrm{ml}$ trypsin plus $0.5 \mathrm{M} \mathrm{NaCl}$ or $1.5 \mathrm{mM}$ NEM. A portion of the trypsin/NaCl-treated adipocytes was reconstituted with trypsin/NaCl-extract. After further incubation $\left(20 \mathrm{~min}, 37^{\circ} \mathrm{C}\right)$ in the absence or presence of increasing concentrations of PIG41, hcDIGs were prepared and used for immunoprecipitation (IP) of caveolin-1 in dissociating buffer. The immunoprecipitates were immunoblotted (IB) for pp $125^{\mathrm{Fak}}$ and pp59 $9^{\mathrm{Lyn}}$.

(A) Chemiluminescent images of a typical experiment repeated two times with similar results. (B) Quantitative evaluations of three different adipocyte incubations with measurements in triplicate each as percent of basal values (absence of PIG41) for control cells (mean $\pm \mathrm{SD}$ ) set at $100 \%$ in each case.

NEM-treated adipocytes with $10 \mu \mathrm{M}$ PIG4l further decreased the amount of caveolin-associated pp5 $59^{\mathrm{Lyn}}$ and pp $125^{\mathrm{Fak}}$ by only $20-45 \%$ and $30-50 \%$, respectively. In reconstituted adipocytes, PIG4I triggered translocation of the NRTKs from hcDIGsassociated caveolin with about the same maximal response and with similar concentration response $\left(\mathrm{EC}_{50} 0.1-0.3 \mu \mathrm{M}\right)$ as in control cells (Fig. 6). The efficiencies of the individual caveolin immunoprecipitations were comparable (data not shown). Complementary to the inhibition of stimulus- dependent dissociation of NRTKs from hcDIGsassociated caveolin, inactivation of CIR (by trypsin/ $\mathrm{NaCl}$ ) diminished the PIG4l-induced 16-fold increment of pp59 $9^{\mathrm{Lyn}}$ at lcDIGs in control cells to 1.6fold (Fig. 7). The 6-fold higher basal and by $50 \%$ reduced PIG4l-dependent translocation to lcDIGs after CIR inactivation was almost completely reversed in reconstituted cells resulting in an about 11 -fold increase of pp59 $59^{\mathrm{Ly}}$ at lcDIGs upon challenge with PIG41. Comparable results were obtained for involvement of CIR in PIG41-dependent 


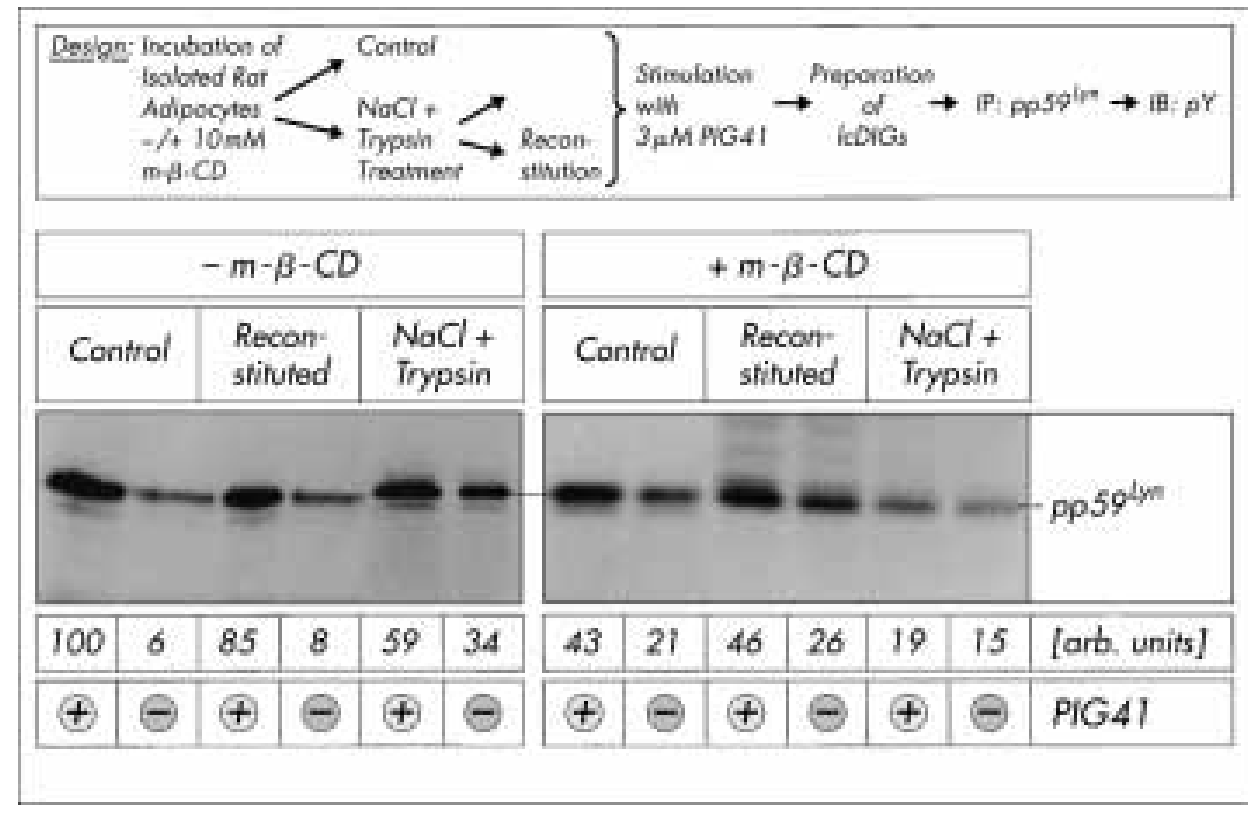

Fig. 7. Effect of cholesterol depletion on the involvement of CIR in activation of pp59 ${ }^{\text {Lyn }}$ by PIG41. Isolated rat adipocytes were incubated in the absence (Control) or presence of $10 \mu \mathrm{g} / \mathrm{ml}$ trypsin plus $0.5 \mathrm{M} \mathrm{NaCl}$. Portion of the trypsin/NaCl-treated adipocytes was reconstituted with trypsin/ $\mathrm{NaCl}$-extract. After further incubation $\left(20 \mathrm{~min}, 37^{\circ} \mathrm{C}\right)$ in the absence or presence of $3 \mu \mathrm{M}$ PIG41, lcDIGs were prepared and used for immunoprecipitation (IP) of $\mathrm{pp} 59^{\mathrm{Lyn}}$ in dissociating buffer. The immunoprecipitates were immunoblotted (IB) for phosphotyrosine (pY). The figure shows chemiluminescent images of a typical experiment repeated three times with similar results. Quantitative evaluations of four different adipocyte incubations are given as means (arbitrary units) with PIG41-treated control cells set at 100 .

translocation of $\mathrm{pp} 125^{\text {Fak }}$ to lcDIGs (data not shown). We did not observe any impairment of glimepiride-induced translocation of $p p 59^{\mathrm{Lyn}}$ and pp $125^{\text {Fak }}$ from hcDIGs to lcDIGs in trypsin/ NaCltreated adipocytes (data not shown) in agreement with previous findings that CIR is not involved in glimepiride-dependent redistribution of NRTKs between DIGs and non-DIG areas (22). These data provide strong evidence for a role of CIR in both retention of NRTKs at hcDIGs in the basal state and their translocation to lcDIGs in response to PIG41.

With the following experiments, these functions of CIR were analyzed in adipocytes depleted of cholesterol by treatment with $\mathrm{m} \beta C D$ (Fig. 7) or $\mathrm{CO}$ (Table 2). The 3.5-fold higher amount of pp59 $9^{\text {Lyn }}$ at lcDIGs of basal cholesterol-depleted versus control cells was slightly reduced by inactivation of CIR and restored by subsequent reconstitution with active CIR. After cholesterol depletion, PIG41 provoked translocation of pp59 $9^{\mathrm{Lyn}}$ to lcDIGs (about 2 -fold at $3 \mu \mathrm{M})$ in control and reconstituted but not trypsin/ NaCl-treated adipocytes (Fig. 7). Stimulation of pp59 ${ }^{\mathrm{Lyn}}$ translocation in response to either PIG41, glimepiride, trypsin/ $\mathrm{NaCl}$ or NEM was nearly additive to the effect of cholesterol depletion by $\mathrm{CO}$ action which almost completely disappeared upon $\mathrm{CO}$ withdrawal (Table 2, $+\mathrm{CO}>-\mathrm{CO}$ ). This argues for distinct translocation mechanisms engaged by cholesterol depletion and these insulin-mimetic stimuli.
This may also explain the observations that only the latter trigger tyrosine phosphorylation of pp59 $9^{\text {Lyn }}$ and IRS- 1 as well as glucose transport activation.

\section{Cholesterol Depletion Inhibits Metabolic Signaling by Insulin-Mimetic Stimuli in Isolated Rat Diaphragms}

Finally we asked whether the apparent role of hcDIGs and lcDIGs in mediating insulin-mimetic metabolic effects is restricted to adipocytes. For this, the effect of cholesterol depletion on stimulation of glycogenesis and glycogen synthase was investigated in a different highly insulin-responsive target tissue, the isolated rat diaphragm (Table 4). Treatment with $\mathrm{m} \beta \mathrm{CD}$ alone but not in the presence of $\mathrm{m} \beta \mathrm{CD}$ complexed to cholesterol $(\mathrm{m} \beta \mathrm{CD}+\mathrm{m} \beta \mathrm{CD}$-chol) impaired activation of both glycogenesis and glycogen synthase in diaphragms in response to maximally effective concentrations of insulin, PIG41 and glimepiride by $50-60 \%$. Basal activities were not altered by either treatment as observed with adipocytes. In contrast, $\mathrm{Na}_{3} \mathrm{VO}_{4}$ - and POV-induced glycogenesis and glycogen synthase activation were not diminished in cholesterol-depleted diaphragms, also excluding loss of cell viability under these conditions (Table 4). Thus, insulin-mimetic metabolic signaling in isolated rat diaphragms upon challenge with PIG4l and glimepiride, but not vanadium compounds, critically depends on the integrity of hcDIGs which may function as source for pp59 $9^{\mathrm{Lyn}}$ for its translocation to and activation at lcDIGs as has been shown above 
Table 4. Effect of cholesterol depletion on stimulation of glycogenesis and glycogen synthase

\begin{tabular}{|c|c|c|c|c|c|c|}
\hline & \multicolumn{3}{|c|}{ Glycogenesis } & \multicolumn{3}{|c|}{ Glycogen Synthase } \\
\hline & Control & $\mathbf{m} \beta C D$ & $\begin{array}{c}\mathbf{m} \beta C D+ \\
\mathbf{m} \beta C D-c h o l\end{array}$ & Control & $\mathrm{m} \beta C D$ & $\begin{array}{c}\mathrm{m} \beta C D+ \\
\mathbf{m} \beta C D-c h o l\end{array}$ \\
\hline Basal & $1.0 \pm 0.2$ & $1.3 \pm 0.3$ & $1.2 \pm 0.2$ & $1.0 \pm 0.3$ & $1.2 \pm 0.2$ & $0.9 \pm 0.2$ \\
\hline $\mathrm{Na}_{3} \mathrm{VO}_{4}$ & $3.9 \pm 0.5$ & $3.3 \pm 0.4$ & $4.0 \pm 0.6$ & $2.6 \pm 0.4$ & $2.9 \pm 0.5$ & $3.1 \pm 0.4$ \\
\hline POV & $4.9 \pm 0.9$ & $5.2 \pm 0.8$ & $5.4 \pm 0.7$ & $3.0 \pm 0.6$ & $3.3 \pm 0.4$ & $3.5 \pm 0.5$ \\
\hline Insulin & $6.8 \pm 1.2$ & $2.5 \pm 0.4$ & $5.9 \pm 0.9$ & $3.5 \pm 0.7$ & $1.5 \pm 0.3$ & $3.2 \pm 0.3$ \\
\hline PIG41 & $7.5 \pm 1.8$ & $2.9 \pm 0.5$ & $6.3 \pm 0.8$ & $3.9 \pm 0.8$ & $1.3 \pm 0.3$ & $3.4 \pm 0.4$ \\
\hline Glim & $2.7 \pm 0.6$ & $1.2 \pm 0.3$ & $3.0 \pm 0.4$ & $2.4 \pm 0.4$ & $1.1 \pm 0.2$ & $2.7 \pm 0.3$ \\
\hline
\end{tabular}

Isolated rat diaphragms were incubated $\left(50 \mathrm{~min}, 30^{\circ} \mathrm{C}\right.$ ) in the absence (control) or presence of $2.3 \mathrm{mM} \mathrm{m} \beta \mathrm{CD}$ or $1.1 \mathrm{mM} \mathrm{m} \beta \mathrm{CD}$ plus $1.1 \mathrm{mM} m \beta C D$-cholesterol complex $\left(\mathrm{m} \beta \mathrm{CD}+\mathrm{m} \beta \mathrm{CD}\right.$-chol) and subsequently with $1 \mathrm{mM} \mathrm{Na} \mathrm{VO}_{4}, 10 \mu \mathrm{M}$ potassium bisperoxo [1,10-phenanthroline] oxovanadate (POV), $50 \mathrm{nM}$ insulin, $3 \mu \mathrm{M}$ PIG41, or $10 \mu \mathrm{M}$ glimepiride (50 min, $37^{\circ} \mathrm{C}$ ). The diaphragms were assayed for glycogenesis or glycogen synthase fractional velocity. Fold stimulations are given with basal values (absence of insulin) obtained with control cells set at 1 . Each value represents the mean \pm SD of three independent diaphragms with single incubations each.

for adipocytes. However, in both rat adipocytes and diaphragms translocation of signaling proteins to lcDIGs as provoked by cholesterol depletion is apparently not sufficient for insulin-mimetic signaling.

\section{Discussion}

Lowering of the adipocyte plasma membrane cholesterol content using $\beta$-cyclodextrin has recently been reported to result in loss of the structural features of caveolae (disappearance of the typical invaginations and flattening) in a concentration-dependent fashion as visualized by transmission electron microscopy (21). Remarkably, this clear-cut morphologic alteration was accompanied by progressive inhibition of insulin-stimulated glucose transport and IRS-1 tyrosine phosphorylation without concomitant impairment of insulin receptor autophosphorylation. In addition, the inhibition of insulin signaling as the result of cholesterol extraction by cyclodextrin was reproduced by cholesterol oxidation (20). Thus, caveolae and DIGs, which presumably represent their biogenetic precursors (12), seem to be involved in coupling the insulin receptor to the IRS proteins. These plasma membrane microdomains may thereby represent a structural prerequisite for functional insulin signaling in insulin target cells, albeit the underlying molecular mechanism remains to be elucidated. The complete blockade of insulin-mimetic signaling and action in response to PIG41 and glimepiride subsequent to disruption of DIGs by cholesterol depletion, as demonstrated in the present study, strongly argues for involvement of DIGs also in insulin- and IR-independent cross-talking to the insulin signaling cascade. The molecular mechanisms underlying the dependence of both "typical" insulin and "atypical" insulin-mimetic signaling on
DIGs of the fat and muscle cell plasma membrane may be completely unrelated.

The present data provide strong evidence that using the criteria of buoyant density, cholesterol content, and relative abundance of lipid-modified signaling proteins, such as GPI proteins and NRTKs, two distinct species of DIGs, so-called hcDIGs of low buoyant density and high cholesterol content and lcDIGs of higher buoyant density and lower cholesterol content, coexist in rat adipocytes even in the unstimulated state. Interestingly, we found that some exogeneous stimuli (incubation of adipocytes with glimepiride and PIG41, introduction of pp59 $9^{\text {Lyn }}$-derived CBDP into adipocytes, treatment of adipocytes with trypsin/ $\mathrm{NaCl}$ and NEM) but not others (incubation of adipocytes with $\mathrm{Na}_{3} \mathrm{VO}_{4}$ and POV), which mimic metabolic insulin action through induction of IRS tyrosine phosphorylation to a partial degree, elicit the translocation of a subset of GPI proteins and NRTKs, such as Gcel and pp59 ${ }^{\text {Lyn }}$, from hcDIGs to lcDIGs. The resultant activation of pp59 $9^{\mathrm{Lyn}}$ seems to be based both on its dissociation from caveolin left at hcDIGs (thus lending credit to the so-called caveolae signaling hypothesis originally proposed byLisanti et al., see ref. 12) and on its proper incorporation at lcDIGs. A proteinaceous cell surface component, CIR, presumably identical with pl15, which is released from adipocytes by trypsin/ $\mathrm{NaCl}$-treatment and can be labeled with NEM (33), may support the role of cholesterol in the formation of hcDIGs and/or in stimulus-dependent translocation of signaling proteins to lcDIGs. It is conceivable that CIR becomes inactivated upon challenge with PIG4l (as is almost certainly true for trypsin/ $\mathrm{NaCl}$ treatment) of rat adipocytes. However, redistribution of signaling proteins from hcDIGs to lcDIGs is required but not 
sufficient for insulin-mimetic signaling to IRS-1; artificial translocation of signaling proteins caused by cholesterol depletion per se failed to elicit IRS-1 tyrosine phosphorylation. This raises the possibility for PIG4l-induced generation of an lcDIGs-independent signal feeding into the DIGs-caveolinpp59 $9^{\mathrm{Lyn}}$-IRS pathway downstream of lcDIGs, which may involve CIR. In addition to a function of CIR in concentrating signaling components at hcDIGs, it might fulfill a specific (catalytic) role in the translocation process of signaling components to lcDIGs in response to a variety of insulin-mimetic stimuli, such as their incorporation into a specific lipidic environment or their oligomerization at lcDIGs. This putative regulatory role of CIR apparently cannot be mimicked by mere cholesterol depletion.

Cholesterol has generally been considered as the major lipid molecule for organizing DIGs, because its removal effectively disrupts caveolae and renders caveolin-1 detergent soluble in various cell types (12-14). The combination of specific cholesterolbinding and oligomerizing properties $(47,48)$ should allow caveolin to function in the mutual enrichment of proteins and lipids to form distinct membrane microdomains, the hcDIGs. Thus it is conceivable that artificial cholesterol depletion interferes with signaling protein-caveolin interactions and oligomer formation within DIGs/caveolae. To enable physiologic regulation, this effect of cholesterol on the function of caveolin could be modified by CIR action. Preliminary data indicate the permanent residence of CIR at hcDIGs, its interaction with caveolin, and oligomerization in rat adipocytes even upon challenge with PIG41, glimepiride, or CBDP. Interestingly, interaction with caveolin and oligomerization of CIR was not observed with adipocytes depleted of cholesterol by $\mathrm{m} \beta \mathrm{CD}$ or $\mathrm{CO}$ treatment (G. Müller, C. Jung, unpublished results). Taken together, these results are compatible with a model of concerted action of cholesterol, caveolin, and CIR in (regulation of) the biogenesis and maintenance of hcDIGs/caveolae rather than of lcDIGs.

Two recent lines of evidence suggested but did not unequivocally demonstrate heterogeneity of plasma membrane microdomains. First, Hancock et al. $(49,50)$ raised the intriguing hypothesis that functional differences between Ras isoforms are due, at least in part, to localization in different plasma membrane microdomains. Using multiple techniques, they showed for the first time that $\mathrm{H}$-Ras and K-Ras have different distributions across caveolae, DIGs, and non-DIG domains according to established criteria, H-Ras to caveolae/DIGs and $\mathrm{K}$-Ras to different membrane microdomains, which, unfortunately, were not further characterized at the biochemical/morphologic level. However, cholesterol depletion caused loss of both K-Ras and H-Ras from caveolar fractions (51), indicating that both $\mathrm{H}-\mathrm{R}$ as and K-Ras are located in cholesterol-rich DIGs. The primary difference between Ras isoforms is their carboxy-terminal membrane targeting sequence. Both $\mathrm{H}$ - and $\mathrm{K}$-Ras are prenylated, but $\mathrm{H}$-Ras is additionally modified by palmitylation whereas K-Ras contains a basic polylysine sequence. Consequently, Prior et al. (49) suggested that the membrane anchors confer targeting specificity for distinct membrane microdomains. This interpretation is in agreement with the current view that targeting of proteins to DIGs is based solely on their lipid modification ([dual] acylation or glypiation) and does not require the direct interaction with caveolin (52-54).

Second, a morphometric analysis of immunogold-labeled microvillar vesicles from the enterocyte brush border membrane immunoisolated with antibodies to either galectin-4 or lactase as marker proteins for DIGs (55) and non-DIG microdomains (56), respectively, revealed the existence of subpopulations of relatively DIG-rich and DIG-poor vesicles (57). Surprisingly, pretreatment with $\mathrm{m} \beta \mathrm{CD}$, which removed more than $70 \%$ of microvillar cholesterol, did not affect the localization of galectin-4 at DIGs, strongly arguing for the simultaneous presence in the enterocyte brush border of stable cholesterolindependent DIGs, which appear to be heterogenous with regard to size and organization, and typical cholesterol-dependent DIGs. It would be interesting to know whether these membrane microdomains acting as putative residence for K-Ras and galectin- 4 are similar/identical to lcDIGs.

In the past, observations of protein localization at plasma membrane microdomains in general, and at DIGs in particular, have often been very controversial $(58,59)$, emphasizing the extraordinary sensitivity of this association toward the techniques used. Further efforts are needed to understand the plasma membrane compartmentalization of (lipidmodified) signaling proteins, in general, and their targeting to/redistribution between hc/lcDIGs, in particular, as well as the resulting functional consequences. Quantitative transmission electron microscopy or evanescent wave microscopy (60) may turn out as an essential technique for assessing localization at DIGs. This could ultimately lead to strategies taking advantage of drug-induced redistribution of signaling proteins between plasma membrane microdomains in signal transduction therapy. For instance, a small molecule drug provoking signaling protein translocation from hcDIGs to lcDIGs in insulin target cells may induce metabolic insulin action independent of insulin and IR activation by engagement of the DIGs-caveolinpp5 $9^{\mathrm{LYn}}$-IRS pathway $(29,34)$.

\section{References}

1. Simons K, Ikonen E. (1997) Functional rafts in cell membranes. Nature 387: 569-572.

2. Brown DA, London E. (2000) Structure and function of sphingolipid- and cholesterol-rich membrane rafts. J. Biol. Chem. 275: 17221-17224. 
3. Simons K, Van Meer G. (1988) Lipid sorting in epithelial cells. Biochemistry 27: 6197-6202.

4. Brown DA, Rose JK. (1992) Sorting of GPI-anchored proteins to glycolipid-enriched membrane subdomains during transport to the apical cell surface. Cell 68: 533-544.

5. Brown DA, London E. (1998) Function of lipid rafts in biological rafts. Аnnu. Rev. Cell Dev. Biol. 14: 111-136.

6. Dupree P, Parton RG, Raposo G, Kurzchalia TV, Simons K. (1993) Caveolae and sorting in the trans-Golgi network of epithelial cells. $E M B O \mathrm{~J}$. 12: 1597-1605.

7. Harder T, Simons K. (1997) Caveolae, DIGs, and the dynamics of sphingolipid-cholesterol microdomains. Curr. Opin. Cell Biol. 9: 534-542.

8. Smart EJ, Ying Y-S, Mineo C, Anderson RGW. (1995) A detergent-free method for purifying caveolae membrane from tissue culture cells. Proc. Natl. Acad. Sci. U.S.A. 92: 10104-10108.

9. Stan RV, Robert WG, Predescu D, et al. (1997) Immunoisolation and partial characterization of endothelial plasmalemmal vesicles (caveolae). Mol. Biol. Cell 8: 595-605.

10. Song SK, Li S, Okamoto T, Quilliam L, Sargiacomo M, Lisanti MP. (1996) Copurification and direct interaction of Ras with caveolin, an integral membrane protein of caveolae microdomains. Detergent free purification of caveolae membranes. J. Biol. Chem. 271: 9690-9697.

11. Lisanti MP, Scherer PE, Tang ZL, Sargiacomo M. (1994) Caveolae, caveolin and caveolin-rich membrane domains: a signaling hypothesis. Trends Cell Biol. 4: 231-235.

12. Schlegel A, Volonte D, Engelmann JA. (1999) Crowded little caves: structure and function of caveolae. Cell. Signal. 10: 457- 463.

13. Shaul PW, Anderson RG. (1998) Role of plasmalemmal caveolae in signal transduction. Am. J. Physiol. 275: L843-L851.

14. Okamoto T, Schlegel A, Scherer PE, Scherer MP. (1998) Caveolins, a family of scaffolding proteins for organizing "preassembled signaling complexes" at the plasma membrane. J. Biol. Chem. 273: 5419-5422.

15. Kurzchalia TV, Parton RG. (1996) And still they are moving . . . Dynamic properties of caveolae. FEBS Lett. 389: 52-54.

16. Smart EJ, Graf GA, McNiven MA, et al. (1999) Caveolins, liquid-ordered domains and signal transduction. Mol. Cell. Biol. 19: 7289-7304.

17. Parton RG. (1996) Caveolae and caveolins. Curr. Opin. Cell Biol. 8: $542-548$.

18. Anderson RGW. (1993) Caveolae: where incoming and outgoing messengers meet. Proc. Natl. Acad. Sci. U.S.A. 90: 1090910913.

19. Scherer PE, Lisanti MP, Baldini G, Sargiacomo M, Mastick C, Lodish HF. (1994) Induction of caveolin during adipogenesis and association of GLUT4 with caveolin-rich vesicles. J. Cell Biol. 127: 1233-1243.

20. Gustavsson J, Parpal S, Karlsson M, et al. (1999) Localization of the insulin receptor in caveolae of adipocyte plasma membrane. FASEB J. 13: 1961-1971.

21. Parpal S, Karlsson M, Thorn H, Stralfors P. (2001) Cholesterol depletion disrupts caveolae and insulin receptor signaling for metabolic control via insulin receptor substrate-1, but not mitogen-activated protein kinase control. J. Biol. Chem. 276: 9670-9678.

22. Müller G, Wied S, Crecelius A, Kessler A, Eckel J. (1997) Phosphoinositolglycan-peptides from yeast potently induce metabolic insulin actions in isolated rat adipocytes, cardiomyocytes, and diaphragms. Endocrinology 138: 3459-3475.

23. Frick W, Bauer A, Bauer J, Wied S, Müller G. (1998) Insulinmimetic signaling of synthetic phosphoinositolglycans in isolated rat adipocytes. Biochem. J. 336: 163-181.

24. Frick W, Bauer A, Bauer J, Wied S, Müller G. (1998) Structureactivity relationship of synthetic phosphoinositolglycans mimicking metabolic insulin action. Biochemistry 37: 1342 1-13436.

25. Stralfors P. (1997) Insulin second messengers. Bioessays 19: 327-35.

26. Jones DR, Varela-Nieto I. (1998) Diabetes and the role of inositol-containing lipids in insulin signaling. Mol. Med. 5: 505-514.
27. Shaskin PN, Wasner HK, Ortmeyer HK, Hansen BC. (2001) Prostaglandylinositol cyclic phosphate (CPIP): a novel second messenger of insulin action. Comparative analysis of two kinds of 'insulin mediators'. Diabetes/Metab. Res. Rev. 17: 273- 284.

28. Nosjean O, Briolay A, Roux B. (1997) Mammalian GPI proteins: sorting, membrane residence and functions. Biochim. Biophys. Acta 1331: 153-186.

29. Müller G. (2000) The molecular mechanism of the insulinmimetic/sensitizing activity of the antidiabetic sulfonylurea drug glimepiride. Mol. Med. 6: 907-933.

30. Couet J, Li S, Okamoto T, Ikezu T, Lisanti MP. (1997) Identification of peptide and protein ligands for the caveolinscaffolding domain. J. Biol. Chem. 272: 6525-6533.

31. Müller G, Wied S, Frick W. (2000) Cross talk of pp $125^{\text {Fak }}$ and pp5 $9^{\text {Lyn }}$ non-receptor tyrosine kinases to insulin-mimetic signaling in adipocytes. Mol. Cell. Biol. 20: 4708-4723.

32. Müller G, Jung C, Wied S, Welte S, Jordan H, Frick W. (2001) Redistribution of glycolipid raft domain components induces insulin-mimetic signaling in rat adipocytes. Mol. Cell. Biol. 21: 4553-4567.

33. Müller G, Wied S, Piossek C, Bauer A, Bauer J, Frick W. (1998) Convergence and divergence of the signaling pathways for insulin and phosphoinositolglycans. Mol. Med. 4: 299-323.

34. Müller G, Frick W. (1999) Signaling via caveolin: involvement in the cross-talk between phosphoinositolglycans and insulin. Cell. Mol. Life Sci. 56: 945-970.

35. Müller G, Jung C, Wied S, Welte S, Frick W. (2001) Insulinmimetic signaling by the sulfonylurea glimepiride and phosphoinositolglycans involves distinct mechanisms for redistribution of lipid raft components. Biochemistry 40: 14603-14620.

36. Müller G, Wetekam E-A, Jung C, Bandlow W. (1994) Membrane association of lipoprotein lipase and a cAMP-binding ectoprotein in rat adipocytes. Biochemistry 33: 12149-12159.

37. Müller G, Dearey E-A, Korndörfer A, Bandlow W. (1994) Stimulation of a glycosyl phosphatidylinositol-specific phospholipase by insulin and the sulfonylurea, glimepiride, in rat adipocytes depends on increased glucose transport. J. Cell Biol. 126: $1267-1276$.

38. Thiele C, Hannah MJ, Fahrenholz F, Huttner WB. (2000) Cholesterol binds to synaptophysin and is required for biogenesis of synaptic vesicles. Nat. Cell Biol. 2: 42-49.

39. Richmond W. (1973) Preparation and properties of a cholesterol oxidase from Nocardia sp. and its application to the enzymatic assay of total cholesterol in serum. Clin. Chem. 19: $1350-1356$.

40. Ohtani Y, Irie T, Uekama K, Fukunaga K, Pitha J. (1989) Differential effects of alpha-, beta- and gamma-cyclodextrins on human erythrocytes. Eur. J. Biochem. 186: 17-22.

41. Christian AE, Haynes MP, Phillips MC, Rothblat GH. (1997) Use of cyclodextrins for manipulating cellular cholesterol content. J. Lipid Res. 38: 2264-2272.

42. Ilangumaran S, Hoessli DC. (1998) Effects of cholesterol depletion by cyclodextrin on the sphingolipid microdomains of the plasma membrane. Biochem. J. 335: 433-440.

43. Munoz P, Mora S, Sevilla L, et al. (1996) Expression and insulin-regulated distribution of caveolin in skeletal muscle. Caveolin does not colocalize with GLUT4 in intracellular membranes. J. Biol. Chem. 271: 8133-8139.

44. Gustavsson J, Parpal S, Stralfors P. (1996) Insulin-stimulated glucose uptake involves the transition of glucose transporters to a caveolae-rich fraction within the plasma membrane: implications for type II diabetes. Mol. Med. 2: 367-372.

45. Anderson RGW. (1998) The caveolae membrane system. Annu. Rev. Biochem. 67: 199-225.

46. Sekar N, Li J, Shechter Y. (1996) Vanadium salts as insulin substitutes: mechanisms of action, a scientific and therapeutic tool in diabetes mellitus research. Crit. Rev. Biochem. Mol. Biol. 31: 339-359.

47. Monier S, Parton RG, Vogel F, Behlke J, Henske A, Kurzchalia TV. (1995) VIP2 1-caveolin, a membrane protein constituent of the caveolar coat, oligomerizes in vitro and in vitro. Mol. Biol. Cell 6: 911-927. 
48. Murata M, Peranen J, Schreiner R, Wieland F, Kurzchalia TV, Simons K. (1995) VIP21 is a cholesterol-binding protein. Proc. Natl. Acad. Sci. U.S.A. 92: 10339-10343.

49. Prior IA, Harding A, Yan J, Sluimer J, Parton RG, Hancock JF. (2001) GTP-dependent segregation of H-ras from lipid rafts is required for biological activity. Nat. Cell Biol. 3: 368-375.

50. Shields JM, Pruitt K, McFall A, Shaub A, Der CJ. (2000) Understanding Ras: 'It ain't over 'til it's over.' Trends Cell Biol. 10: 147-154.

51. Furuchi T, Anderson RGW. (1998) Cholesterol depletion of caveolae causes hyperactivation of extracellular signalregulated kinase (ERK) J. Biol. Chem. 273: 21099-21104.

52. Melkonian KA, Ostermeyer AG, Chen JZ, Roth MG, Brown DA. (1999) Role of lipid modifications in targeting proteins to detergent-resistant membrane rafts. Many raft proteins are acylated, while few are prenylated. J. Biol. Chem. 274: 39103917.

53. Rothberg KG. (1995) Caveolar targeting of glycosylphosphatidylinositol-anchored proteins. Meth. Enzymol. 250: 669682.

54. Villar A-V, Alonso A, Paneda C, Varela-Nieto I, Brodbeck U, Goni F-M. (1999) Towards the in vitro reconstitution of cave- olae. Asymmetric incorporation of glycosylphosphatidylinositol (GPI) and gangliosides into liposomal membranes. FEBS Lett. 457: 71-74.

55. Danielsen EM, van Deurs B. (1997) Galectin-4 and small intestinal brush border enzymes form clusters. Mol. Biol. Cell 8: 2241-2251.

56. Danielsen EM. (1995) Involvement of detergent-insoluble complexes in the intracellular transport of intestinal brush border enzymes. Biochemistry 34: 1596-1605.

57. Hansen GH, Immerdal L, Thorsen E, et al. (2001) Lipid rafts exist as stable cholesterol-independent microdomains in the brush border membrane of enterocytes. J. Biol. Chem. 276: 32338-32344.

58. Kurzchalia TV, Hartmann E, Dupre P. (1995) Guilt by insolubility-does a protein's detergent insolubility reflect a caveolar location? Trends Cell Biol. 5: 187-189.

59. Friedrichson T, Kurzchalia TV. (1998) Microdomains of GPIanchored proteins in living cells revealed by crosslinking. Nature 394: 802-805.

60. Toomre D, Manstein DJ. (2001) Lighting up the cell surface with evanescent wave microscopy. Trends Cell Biol. 11 : 298-303. 